\title{
Caracterização ecológica e fitoquímica de quatro populações naturais de Maytenus ilicifolia no Estado do Paraná
}

\author{
Maria Izabel Radomski(1), Leonardo Theodoro Bull(2)
}

(1) Embrapa Florestas, Estrada da Ribeira, Km 111, CP 319, Colombo, PR, CEP 83411-000, izabel@cnpf.embrapa.br; (2) Unesp Botucatu, Distrito de Rubião Junior, s/nº, Botucatu, SP, CEP 18618-000, bull@fca.unesp.br

\begin{abstract}
Resumo - A espécie medicinal Maytenus ilicifolia (Mart. ex Reiss.) localiza-se naturalmente sob diferentes condições edafoclimáticas. Isto implica em prováveis mecanismos de adaptação das populações naturais, cujas características químicas podem estar fixadas geneticamente. Este estudo foi desenvolvido para determinar a influência do ambiente sobre a composição fitoquímica de M. ilicifolia. Amostras de plantas foram coletadas em quatro populações naturais localizadas sobre diferentes superfícies geológicas no Estado do Paraná e sob distintas condições de luminosidade (pleno sol, meia sombra e sombra). Os solos foram classificados segundo o Sistema Brasileiro de Classificação. Foram avaliados os teores foliares de N, P, K, Ca, Mg, Fe, Mn, Cu, Zn, $\mathrm{Si}, \mathrm{Al}$, lignina, fenóis totais, fenóis não tanantes e taninos, e a massa específica foliar. Os resultados indicam que $M$. ilicifolia apresenta plasticidade ambiental, ocorrendo em distintas condições de fertilidade e regime hidromórfico dos solos. Também foi observado que é possível controlar a síntese de lignina e taninos em $M$. ilicifolia por meio da disponibilidade de luz.
\end{abstract}

Termos para indexação: Espinheira-santa, lignina, tanino, silício.

\section{Ecological and phytochemical characterization of four natural populations of Maytenus ilicifolia at Parana State, Brazil}

\begin{abstract}
Maytenus ilicifolia (Mart. ex Reiss.) is a medicinal species that occurs naturally on different soils and light conditions. This involves adaptation mechanisms of the natural populations whose chemical characteristics may be genetically determined. This study was developed to determine the influence of the environment in the phytochemical content of M. ilicifolia. The plant samples were collected from four natural communities on distinct geological regions at Parana State and under different light conditions (full sun middle shade and shade). The soils were classified according to the Brazilian Classification System. The specific leaf mass was determined as well the total content of $\mathrm{N}, \mathrm{P}, \mathrm{K}, \mathrm{Ca}, \mathrm{Mg}, \mathrm{Fe}, \mathrm{Mn}, \mathrm{Cu}, \mathrm{Zn}, \mathrm{Si}, \mathrm{Al}$, lignin, total phenols and tannins. This study indicates that M. ilicifolia occurs in an indistinct fertility and hydrological gradient of soils. Also, it was found out that the content of lignin and tannin of M. ilicifolia can be controlled by the light availability.
\end{abstract}

Index-terms: Espinheira-santa; lignin; tannin; silicon.

\section{Introdução}

A espécie Maytenus ilicifolia (Mart. Ex Reiss.), popularmente conhecida como espinheira-santa, pertence à ordem Celastrales, família Celastraceae, a qual engloba 50 gêneros, compreendendo 800 espécies distribuídas nos trópicos e apenas alguns gêneros nas regiões temperadas. A espécie predomina nos estados da região Sul do Brasil, e nos países vizinhos, Paraguai, Uruguai e leste da Argentina (Carvalho-Okano, 1992).

No Brasil, M. ilicifolia apresenta uma distribuição predominantemente subtropical, ocorrendo em regiões onde o tipo climático predominante é o $\mathrm{Cfb}$, com temperatura média do mês mais quente de $22{ }^{\circ} \mathrm{C}$, temperatura média do mês mais frio superior a $10{ }^{\circ} \mathrm{C}$ e precipitação média anual de $1.500 \mathrm{~mm}$ (CarvalhoOkano, 1992; Leite, 1994).

No Paraná, M. ilicifolia pode ocorrer em clima do tipo Cfa como um elemento raro na vegetação, em áreas de contato das Florestas Estacional Semidecidual e Ombrófila Densa com a Floresta Ombrófila Mista. Estudos têm identificado populações distribuídas sobre diferentes litologias e classes de solo; também se observa que a espécie é tolerante a diferentes regimes de 
saturação hídrica do solo. Entretanto, tem-se constatado que quanto mais próximo o lençol freático da superfície, mais rara a sua ocorrência (Mazza et al., 2003; Radomski et al., 2004b).

O primeiro relato sobre os efeitos terapêuticos da espinheira-santa, especificamente no tratamento de úlceras, foi feito em dezembro de 1922, pelo Dr. Aluizio França, Professor de Terapêutica da Faculdade de Medicina do Paraná (Stellfeld, 1934).

Bernardi \& Wasicky (1959) foram os primeiros autores a relatar a presença de substâncias tânicas em diferentes tipos de folhas de M. ilicifolia. O teor de taninos em folhas coletadas de diversos ambientes revelou grande variação, fato associado às características morfológicas e às condições de insolação. Segundo os autores, folhas de sol apresentaram menor comprimento e maior concentração de substâncias tânicas.

$\mathrm{O}$ efeito terapêutico de extratos aquosos de $M$. ilicifolia no combate às úlceras gástricas foi identificado por Carlini (1988), que comenta que esta ação pode, em parte, ser atribuída à presença dos taninos. Recentemente, o Ministério da Saúde incluiu a espécie na lista de medicamentos fitoterápicos distribuídos à população por meio do Sistema Único de Saúde (SUS) (BRASIL, 2007).

Estudos recentes têm revelado uma divergência nos teores foliares de taninos nas amostras avaliadas, o que indica, dentre outros fatores, uma provável interação entre genótipo e ambiente, resultando em respostas diferenciadas na produção destes compostos (Radomski et al., 2004b).

Diferenças significativas entre teores de elementos minerais e de polifenóis para indívíduos de uma mesma população de $M$. ilicifolia, crescendo sob diferentes condições edafoclimáticas, foram registradas por Radomski et al. (2004a). Em ambientes de sombra, os teores foliares de $\mathrm{Si}, \mathrm{N}, \mathrm{K}$ e B foram superiores, e os teores de polifenóis, inferiores, em relação às plantas crescendo a pleno sol. Segundo os autores, a relação inversa entre a presença de $\mathrm{Si}$ e de compostos polifenólicos poderia ser atribuída ao papel do Si na defesa da planta, no caso de ambientes de sombra, onde a síntese dos polifenóis é reduzida pela menor disponibilidade de luz.

Bittencourt (2000), estudando a variabilidade genética em populações naturais do Estado do Paraná, cita que a estrutura genética da espinheira-santa está intimamente relacionada ao microambiente dos solos onde estas se desenvolveram. Por outro lado, Scheffer (2001), em estudo com diferentes progênies, conclui que a maior parte da variação genética concentra-se dentro das populações, a identidade genética entre as populações diminui à medida que aumenta a distância geográfica entre as mesmas e que, aparentemente, não ocorre interação genótipo x ambiente em espinheira-santa. Considerando que, na sua área de ocorrência natural, M. ilicifolia ocorre em diferentes condições ambientais, cabe analisar até que ponto estas foram incorporadas geneticamente, influenciando a síntese de substâncias bioativas de interesse terapêutico. Este fato é de grande relevância em função da atual demanda e necessidade de padronização da matéria-prima destinada à produção de fitoterápicos com base em M. ilicifolia.

O objetivo deste trabalho foi caracterizar ambientes de ocorrência natural de M. ilicifolia, no Estado do Paraná, e identificar a influência dos mesmos sobre os teores foliares de macro e micronutrientes, $\mathrm{Si}, \mathrm{Al}$, polifenóis totais e taninos.

\section{Material e Métodos}

\section{Seleção e caracterização dos ambientes de ocorrência natural de $M$. ilicifolia}

Foram selecionadas quatro populações naturais, distribuídas nas três regiões fisiográficas do Estado do Paraná:

- Uma população na Região Metropolitana de Curitiba (Primeiro Planalto), denominada RMC;

- Uma população na Floresta Nacional de Irati (Segundo Planalto), denominada Flona;

- Duas populações na Região de Guarapuava (Terceiro Planalto), estando uma localizada na área da Fundação para o Desenvolvimento da Região Centro-Oeste, denominada Rureco, e outra na fazenda da empresa Manasa Florestal - Madeireira Nacional S.A., localizada no distrito da Palmeirinha, denominada Manasa.

As três regiões apresentam as seguintes características:

- Primeiro Planalto: é a zona de eversão entre a Serra do Mar e a escarpa Devoniana, a qual constitui, a oeste, o limite oriental dos sedimentos da Bacia do Paraná. Apresenta duas porções bem distintas - a região de Curitiba, na parte meridional, caracterizada por topografia ondulada, com colinas suavemente arredondadas e altitude uniforme $(850 \mathrm{~m}$ a $950 \mathrm{~m})$, e a parte setentrional, marcada por relevo mais enérgico, onde dominam cabeços de estrato, espigões e vales 
alongados. A população estudada encontra-se na primeira porção, particularmente nas áreas de depósitos fluviais recentes, onde ocorrem solos hidromórficos, gleizados ou não, e solos orgânicos, e também sobre a Formação Guabirotuba, onde ocorrem predominantemente os Cambissolos (Embrapa, 1984).

- Segundo Planalto: constitui-se exclusivamente de rochas sedimentares da Era Paleozóica e rochas ígneas intrusivas, comportando-se como um imenso patamar de denudação, com altitudes de $1.100 \mathrm{~m}$ a $1.200 \mathrm{~m}$. A área da Flona caracteriza-se, particularmente, pela presença de sedimentos argilo-arenosos, pertencentes à formação Palermo (grupo Tubarão), além de feições geomórficas resultantes da ocorrência de diques de diabásio. A população natural estudada compreende indivíduos localizados nas planícies aluvionares dos rios Imbituva e Imbituvão, em altitudes que variam de $790 \mathrm{~m}$ a $820 \mathrm{~m}$, onde predominam Neossolos e Cambissolos hidromórficos (Oliveira, 1999).

- Terceiro Planalto: representa a região dos grandes derrames de magma, sendo que a região em questão caracteriza-se pelos derrames ácidos, do Grupo Chapecó. As populações de espinheira-santa encontram-se sobre solos derivados da decomposição de rochas eruptivas ácidas que compõem o planalto de Guarapuava (Embrapa, 1984).

Nas regiões de estudo, o tipo climático predominante é o $\mathrm{Cfb}$ - sempre úmido, com temperatura média do mês mais quente de $22{ }^{\circ} \mathrm{C}$, temperatura média do mês mais frio superior a $10{ }^{\circ} \mathrm{C}$, mais de cinco geadas noturnas por ano e precipitação média anual em torno dos $1.500 \mathrm{~mm}$; a vegetação original é a Floresta Ombrófila Mista (Floresta com Araucária), associada à Estepe Gramíneo-Lenhosa na região de Guarapuava e Ponta Grossa (Leite, 1994).

Para a caracterização química e granulométrica dos solos, foram efetuadas duas amostragens:

- Tradagem para coleta de horizontes e classificação dos solos, segundo o Sistema Brasileiro de Classificação de Solos (Santos et al., 2006);

- Abertura de trincheiras junto ao tronco dos 40 indivíduos selecionados, para coleta de amostras nas profundidades de $0-5 \mathrm{~cm}, 5-10 \mathrm{~cm}, 10-15 \mathrm{~cm}$ e $15-20$ $\mathrm{cm}$. Estas amostras foram secas a $60{ }^{\circ} \mathrm{C}$, destorroadas e peneiradas à fração $2 \mathrm{~mm}$, sendo realizadas as seguintes análises, de acordo com Embrapa (1999): pH em solução $0,01 \mathrm{M}$ de cloreto de cálcio; Acidez potencial $\left(\mathrm{H}^{+}+\mathrm{Al}^{+3}\right)$

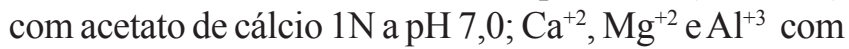
cloreto de potássio $1 \mathrm{~N}, \mathrm{~K}^{+}$com ácido clorídrico $0,05 \mathrm{~N}$;
P com extrator de Mehlich; C total determinado pelo método Walkley e Black, amostras com peso entre $0,1 \mathrm{~g}$ e $0,5 \mathrm{~g} ; \mathrm{Fe}^{+2}, \mathrm{Mn}^{+2}, \mathrm{Cu}^{+}$e $\mathrm{Zn}^{+2}$ disponíveis (extração com $\mathrm{HCl}$ 0,1 N e leitura em espectrofotômetro de absorção atômica); Si disponível por colorimetria, com extrator cloreto de cálcio 0,01 mol.L-1 , segundo Korndörfer et al. (1999a); Granulometria pelo Método da Pipeta.

O ambiente lumínico das populações foi caracterizado por meio da quantidade de luz incidente, medindo-se a radiação fotossinteticamente ativa (PAR $-400 \mathrm{~nm}$ a $700 \mathrm{~nm}$ ) com o equipamento Li-Cor Quantum; e da qualidade da luz incidente, medindo-se a energia radiante do vermelho (655-665 nm), e vermelho-extremo (725$735 \mathrm{~nm}$ ), com o equipamento - SKYE MO, obtendo-se a relação entre vermelho e vermelho-extremo (R:FR) de acordo com a seguinte razão (Taiz \& Zeiger, 2004):

R:FR $=$ Taxa de fluência de fótons em bandas de $10 \mathrm{~nm}$ centradas em $660 \mathrm{~nm}$ Taxa de fluência de fótons em bandas de $10 \mathrm{~nm}$ centradas em $730 \mathrm{~nm}$

Os equipamentos foram instalados junto a indivíduos que representassem cada uma das três condições básicas de ambiente lumínico em que se encontravam as populações - pleno sol, meia sombra (incidência direta de luz solar por pelo menos parte do dia) e sombra (ausência de incidência direta de luz solar). Para realização das leituras, os equipamentos foram posicionados a $1,30 \mathrm{~m}$ de altura do solo, junto à copa das árvores e voltados para a direção norte. Como o objetivo da medição era caracterizar minimamente os ambientes quanto à quantidade e qualidade da luz, optou-se por efetuar os registros em estações extremas do ano: no verão, estação de pleno crescimento, com leituras realizadas em fevereiro de 2005; e no inverno, com leituras em agosto de 2005, ambas no período das $07 \mathrm{~h} 00$ às $19 \mathrm{~h} 00$. Os dados obtidos foram inseridos em planilha eletrônica para sua conversão em gráficos que caracterizassem a PAR e a R:FR, de cada ambiente lumínico nas duas estações.

Foram amostrados dez indivíduos de cada uma das quatro populações naturais, durante o outono (abril de 2005), época em que finaliza a estação de crescimento e a espécie entra em repouso vegetativo e quando tradicionalmente se coletam as folhas para a comercialização. Os indivíduos foram selecionados considerando-se as seguintes características: indivíduos adultos, vigorosos, com copa ampla e galhos com grande quantidade de folhas. De cada indivíduo coletaram-se ramos do terço médio da copa, separando-se para a análise 
folhas plenamente expandidas entre a porção mediana e terminal do ramo. Do material coletado de cada uma das quatro populações, foram selecionadas, aleatoriamente, 100 folhas (Haag, 1983), para determinação da área (em planímetro Modelo AAC-400) e da massa seca. A partir destas variáveis, foi calculada a massa específica das folhas, dividindo-se a massa de 100 folhas, em gramas, por sua área foliar, em $\mathrm{cm}^{2}$. O restante da amostra coletada foi submetido às seguintes determinações da composição fitoquímica:

- Elementos químicos totais: N, P, K, Ca, Mg, Fe, $\mathrm{Mn}, \mathrm{Cu}, \mathrm{Zn}, \mathrm{Al}$, conforme Silva (1999), sendo o N determinado pelo método Kjeldhal e o P pelo método colorimétrico com vanadato-molibdato de amônio e as leituras realizadas em espectrofotômetro UV/VIS 554 Perkin-Elmer; o Si foi determinado pelo método amarelo-vanadato (Korndörfer et al., 1999a), adaptandose a digestão das amostras para forno de micro-ondas.

- Polifenóis totais e taninos: Em 0,25 g do material foliar seco e moído, foram adicionados $250 \mathrm{ml}$ de água deionizada. Esta mistura foi fervida em refluxo durante 30 minutos e filtrada. O extrato aquoso foi submetido à determinação dos polifenóis, segundo metodologia descrita por Reicher et al. (1981).

- Lignina: Determinada pelo método do àcido sulfúrico a $72 \%$ (v/v), segundo Nogueira \& Souza (2005).

As variáveis de solo e plantas analisadas foram submetidas à comparação de médias (teste de Duncan a 5\%), e matriz de correlação; os dados referentes às plantas também foram submetidos à análise de agrupamento (Cluster), transformando-se todas as variáveis analisadas a partir da fórmula: $\mathrm{xi} / \mathrm{Mx}$, onde $\mathrm{M}$ = média; as distâncias foram calculadas pela fórmula: 1 - Pearson $r$, onde $r=$ coeficiente de correlação (Johnson \& Wichern, 1992).

\section{Resultados e Discussão}

\section{Caracterização dos ambientes de ocorrência natural das populações de $M$. ilicifolia}

$\mathrm{Na}$ Tabela 1 estão relacionadas as informações do meio físico (posição geomórfica e classes de solo) e o ambiente lumínico (pleno sol, meia sombra e sombra), observadas para as diferentes populações.

Tabela 1. Posição geomórfica, classe dos solos e ambiente lumínico das quatro populações naturais de Maytenus ilicifolia estudadas no Paraná.

\begin{tabular}{|c|c|c|c|}
\hline População & Posição geomórfica & Classe do solo & $\begin{array}{l}\text { Ambiente } \\
\text { lumínico }\end{array}$ \\
\hline Manasa & Terço superior de encosta (10 indivíduos) & $\begin{array}{l}\text { Associação Neossolo Litólico húmico típico, textura } \\
\text { média com cascalho pedregoso, relevo plano a suave } \\
\text { ondulado, com afloramentos de rocha (RLh) }\end{array}$ & Pleno sol \\
\hline Rureco & Terço médio de encosta (10 indivíduos) & $\begin{array}{l}\text { Cambissolo Háplico } \mathrm{Tb} \text { distrófico A proeminente, } \\
\text { textura muito argilosa, relevo suave ondulado (CXbd) }\end{array}$ & Meia sombra \\
\hline \multirow{4}{*}{ Flona } & $\begin{array}{l}\text { Dique marginal em plaino aluvial de várzea } \\
\text { em superfície de umbral ( } 2 \text { indivíduos })\end{array}$ & $\begin{array}{l}\text { Gleissolo Háplico Tb distrófico típico Epieutrófico A } \\
\text { moderado, textura média, relevo plano fase soterrado } \\
\text { (camada antrópica) (GXbd-fs) }\end{array}$ & \multirow[b]{2}{*}{ Meia sombra } \\
\hline & $\begin{array}{l}\text { Dique marginal em plaino aluvial de } \\
\text { várzea do Rio das Antas, em superfície de } \\
\text { agradação (4 indivíduos) }\end{array}$ & $\begin{array}{l}\text { Gleissolo Háplico Tb distrófico A moderado, textura } \\
\text { argilosa, relevo plano (GXbd) }\end{array}$ & \\
\hline & Plaino aluvial de várzea (3 indivíduos) & $\begin{array}{l}\text { Cambissolo Flúvico Tb distrófico típico A proeminente, } \\
\text { textura muito argilosa, relevo plano (CUbd) }\end{array}$ & Sombra \\
\hline & Plaino aluvial fase paleoterraço ( 1 indivíduo) & $\begin{array}{l}\text { Latossolo Vermelho-Amarelo distrófico A proeminente, } \\
\text { textura argilosa, relevo plano (LVAd) }\end{array}$ & Pleno sol \\
\hline \multirow{3}{*}{ RMC } & $\begin{array}{l}\text { Dique marginal em plaino aluvial de várzea } \\
\text { em superfície de umbral ( } 2 \text { indivíduos })\end{array}$ & $\begin{array}{l}\text { Cambissolo Flúvico Tb distrófico típico A proeminente, } \\
\text { textura média, relevo plano (CUbd) }\end{array}$ & Sombra \\
\hline & $\begin{array}{l}\text { Dique marginal em plaino aluvial de várzea } \\
\text { em superfície de degradação ( } 2 \text { indivíduos) }\end{array}$ & $\begin{array}{l}\text { Neossolo Flúvico Tb distrófico A proeminente, textura } \\
\text { argilosa, relevo plano (RUbd) }\end{array}$ & Meia sombra \\
\hline & Plaino aluvial de várzea (6 indivíduos) & $\begin{array}{l}\text { Cambissolo Húmico distrófico A proeminente, textura } \\
\text { argilosa, relevo plano }(\mathrm{CHd})\end{array}$ & Sombra \\
\hline
\end{tabular}




\section{Características lumínicas}

Nas Figuras 1 e 2 estão representados os valores da radiação fotossinteticamente ativa (PAR), incidente nas plantas no período do inverno e do verão, respectivamente. No verão, os valores da PAR são destacadamente superiores a pleno sol, com média de $6.221 \mu \mathrm{mol} . \mathrm{m}^{-}$ ${ }^{2} \cdot \mathrm{s}^{-1}$ ao longo do dia, sendo que, na meia sombra e sombra, a radiação incidente foi, respectivamente, $44 \%$ e $38 \%$ inferiores, com valores médios de 2.710 $\mu \mathrm{mol} . \mathrm{m}^{-2} . \mathrm{s}^{-1}$ e $2.385 \mu \mathrm{mol} . \mathrm{m}^{-2} . \mathrm{s}^{-1}$. Ainda no verão, o efeito do dossel sobre a quantidade de luz incidente fica evidente quando se observa o comportamento das curvas ao longo do dia - na sombra e meia sombra, a radiação incidente oscila ao longo da manhã, enquanto que a pleno sol os valores aumentam ligeiramente ao longo do dia até por volta das $15 \mathrm{~h} 30$, quando as curvas começam a decrescer igualmente em todos os ambientes. No inverno, os valores de PAR foram inferiores aos do verão, verificando-se um comportamento mais homogêneo entre os ambientes, com valores médios de $1.357 \mu \mathrm{mol} . \mathrm{m}^{-2} . \mathrm{s}^{-1}$ a pleno sol, $1.420 \mu \mathrm{mol} . \mathrm{m}^{-2} . \mathrm{s}^{-1}$ à meia sombra e 1.057 à sombra, praticamente constante ao longo do dia, no ambiente de sombra.

A variação na quantidade de luz disponível no verão indica diferentes taxas assimilatórias para as populações, resultando em diferentes acúmulos de biomassa e efeitos diretos na composição fitoquímica, ambas avaliadas após a estação de crescimento.

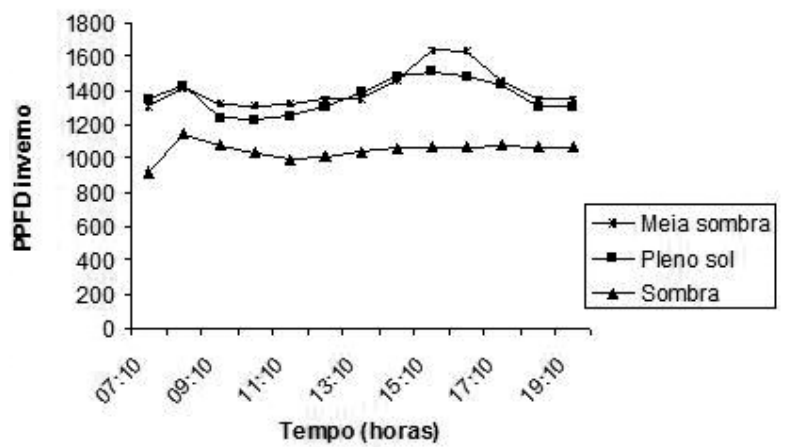

Figura 1. Densidade fotossintética de fluxo fotônico (PPFD) durante o inverno, para os três ambientes lumínicos das populações naturais de Maytenus ilicifolia.
A relação R:FR apresentou comportamento bastante distinto, entre ambientes e entre estações. Na população a pleno sol, a R:FR foi praticamente constante ao longo do dia, com valor médio de 0,97 no verão, e 0,91 no inverno. Nas populações sombreadas, o efeito do dossel na qualidade da luz incidente nos indivíduos de $M$. ilicifolia foi mais acentuado no inverno, com valores de radiação do vermelho e vermelho extremo bastante próximas, resultando numa média de 0,99, enquanto no verão a relação ficou em 0,70 , com uma diminuição da incidência de vermelho $(\mathrm{R})$ em relação ao vermelho-extremo (FR). A razão R:FR diminui com o sombreamento e, em comparação com a luz solar direta, há relativamente mais luz vemelho-extremo durante o pôr-do-sol, em uma profundidade de $5 \mathrm{~mm}$ de solo, ou sob um dossel de outras plantas, como no sub-bosque de uma floresta (Varlet-Grancher et al., 1993). No caso do dossel, as folhas verdes absorvem a luz vermelha, devido ao seu alto teor de clorofila, sendo relativamente transparentes ao vermelho-extremo. Baixas relações R:FR normalmente estão associadas a baixos valores de PAR (Turnbull, 1991), o que foi verificado particularmente para a população Rureco (meia sombra), tanto no verão quanto no inverno.

As Figuras 3 e 4 mostram a razão entre luz vermelha e vermelho-extremo - R:FR, para os três ambientes lumínicos, no inverno e no verão.

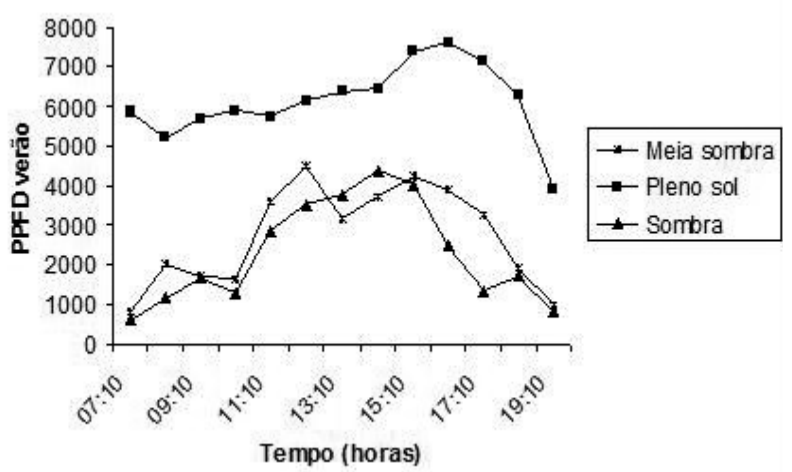

Figura 2. Densidade fotossintética de fluxo fotônico (PPFD) durante o verão, para os três ambientes lumínicos das populações naturais de Mautenus ilicifolia. 


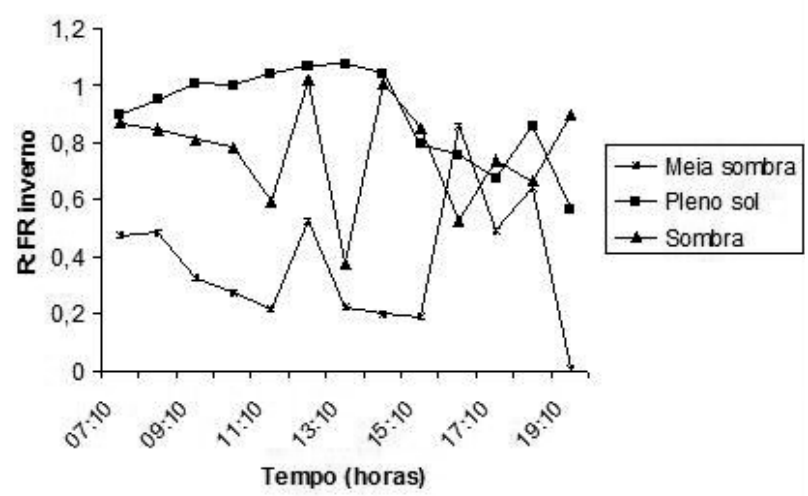

Figura 3. Razão vermelho:vermelho-extremo (R:FR) durante o inverno, para os três ambientes lumínicos das populações naturais de Maytenus ilicifolia.

\section{Características edáficas}

$\mathrm{Na}$ Tabela 2 encontram-se relacionadas as características químicas dos solos das quatro populações estudadas. Verifica-se que a espinheira-santa ocorre sobre diferentes classes de solo - profundos e bem drenados (Latossolo Vermelho-Amarelo distrófico, Cambissolo Háplico Tb distrófico), rasos e moderadamente drenados (Neossolo Litólico húmico típico com afloramentos de rocha), e medianamente profundos e imperfeitamente drenados (Gleissolo Háplico Tb distrófico, Cambissolo Flúvico Tb distrófico e Neossolo Flúvico Tb distrófico). Independente do material de origem, todos os solos apresentam baixa fertilidade natural e caráter ácido. Entretanto, a posição dos solos no relevo e os altos teores de matéria orgânica contribuem com uma maior concentração de nutrientes nas camadas mais superficiais (Tabela 3). Pode-se observar que os solos das superfícies plaino-aluvionares, particularmente os localizados nos diques marginais dos rios que margeiam as populações, apresentam maior saturação em bases (V\%). Este fato se deve à deposição de sedimentos provenientes de áreas a montante destas populações e que contribuem com nutrientes erodidos e/ou lixiviados dos solos das superfícies superiores.

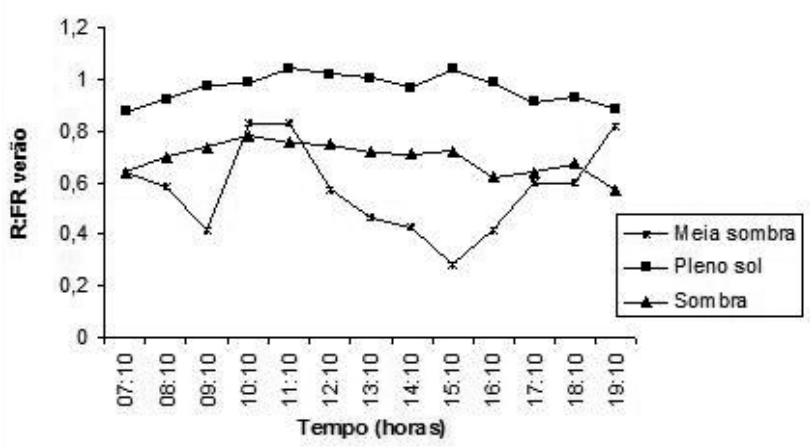

Figura 4. Razão vermelho:vermelho-extremo (R:FR) durante o verão, para os três ambientes lumínicos das populações naturais de Maytenus ilicifolia.

Chamam a atenção os altos teores de P disponível e V\% das camadas superiores dos solos sob a população RMC (Tabela 3). Esta população está localizada em mata ciliar à jusante de área de produção intensiva de hortaliças, e os teores de $\mathrm{P}, \mathrm{Ca}$ e $\mathrm{Mg}$ encontrados nos solos CUbd e RUbd devem-se à constante deposição de sedimentos pelo Rio Palmital, que margeia a área, contribuindo para uma maior fertilidade nas áreas de ocorrência natural de M. ilicifolia. Esta condição de alta fertilidade promovida por ações antrópicas pode influenciar a absorção de nutrientes e a síntese de compostos secundários, como os polifenóis, diferenciando as características químicas desta população em relação às demais, onde o ambiente encontra-se menos alterado.

Em relação ao Si, apesar das diferentes litologias de origem dos solos deste estudo, os teores obtidos foram superiores aos observados nos trabalhos de Korndörfer et al. (1999a, 1999b), Carvalho et al. (2000) e CarvalhoPupatto et al. (2004). Observando os teores do elemento ao longo dos perfis (Tabela 2), verificam-se poucas diferenças, fato relacionado ao baixo intemperismo da maior parte dos solos e ao alto teor de argila dos horizontes (Tabela 4). 
Tabela 2. Características químicas dos solos sob as populações naturais de Maytenus ilicifolia.

\begin{tabular}{|c|c|c|c|c|c|c|c|c|c|c|c|c|c|c|c|c|c|}
\hline \multirow{3}{*}{$\begin{array}{l}\text { População/ } \\
\text { Solo }\end{array}$} & \multirow{3}{*}{$\begin{array}{l}\begin{array}{c}\text { Horizonte } \\
\text { (cm) }\end{array} \\
\text { Ap }(0-19)\end{array}$} & \multirow{3}{*}{$\begin{array}{c}\mathbf{p H} \\
\mathbf{C a C l}_{2}\end{array}$} & $\mathrm{Fe}$ & Mn & $\mathrm{Cu}$ & Zn & $\mathbf{S i}$ & $\mathbf{K}$ & $\mathrm{Ca}$ & Mg & Al & $\mathbf{H}+\mathbf{A l}$ & CTC & \multirow{3}{*}{$\begin{array}{c}\begin{array}{c}\mathbf{P} \\
\mathbf{( m g . d m}^{-3}\end{array} \\
10,9\end{array}$} & \multirow{3}{*}{$\begin{array}{r}\mathbf{C} \\
7,27\end{array}$} & \multirow{3}{*}{$\begin{array}{c}\mathrm{V} \\
(\%) \\
17,5\end{array}$} & \multirow{3}{*}{$\begin{array}{l}\mathbf{m} \\
12,7\end{array}$} \\
\hline & & & \multicolumn{5}{|c|}{$\left(\mathrm{mg} \mathrm{kg}^{-1}\right)$} & \multicolumn{6}{|c|}{$\left(\mathrm{cmol}_{\mathrm{c} .} \mathrm{dm}^{-3}\right)$} & & & & \\
\hline & & & 23 & 82 & 1 & 3 & 12 & 0,33 & 1,43 & 0,53 & 1,67 & 10,81 & 13,1 & & & & \\
\hline \multirow{5}{*}{$\begin{array}{l}\text { Rureco } \\
\text { CXbd }\end{array}$} & A1 $(0-45)$ & 4,10 & 81 & 84 & 45 & 8 & 10,0 & 0,25 & 0,97 & 0,70 & 2,38 & 11,69 & 13,6 & 1,9 & 3,73 & 14,2 & 17,5 \\
\hline & A2 (45-90) & 4,22 & 54 & 57 & 10 & 9 & 11,6 & 0,06 & 0,41 & 0,24 & 1,48 & 9,35 & 10,1 & 0,7 & 2,29 & 7,2 & 14,7 \\
\hline & AB (90-120) & 4,33 & 36 & 33 & 36 & 7 & 11,0 & 0,06 & 0,22 & 0,14 & 1,10 & 8,36 & 8,78 & 1,3 & 1,89 & 4,9 & 12,5 \\
\hline & $\mathrm{BA}(120-150)$ & 4,61 & 54 & 23 & 8 & 5 & 11,6 & 0,03 & 0,29 & 0,05 & 0,32 & 5,55 & 5,92 & 0,6 & 1,40 & 6,3 & 5,4 \\
\hline & Bi $(150-180+)$ & 4,70 & 63 & 30 & 18 & 5 & 12,4 & 0,02 & 0,30 & 0,01 & 0,13 & 4,78 & 5,11 & 0,8 & 0,91 & 6,5 & 2,5 \\
\hline \multirow{5}{*}{$\begin{array}{l}\text { Flona } \\
\text { GXbd-fs }\end{array}$} & $\mathrm{Apb}(0-20)$ & 4,68 & 279 & 334 & 5 & 4 & 14,6 & 0,40 & 7,94 & 2,81 & 0,34 & 5,35 & 16,5 & 5,4 & 1,22 & 53,4 & 2,1 \\
\hline & A1 (20-38) & 4,31 & 270 & 185 & 4 & 4 & 7,8 & 0,27 & 6,14 & 0,9 & 1,12 & 6,44 & 13,8 & 4,5 & 1,31 & 67,8 & 8,1 \\
\hline & $\mathrm{Cg} 1$ (38-57) & 3,94 & 333 & 180 & 7 & 3 & 10,8 & 0,12 & 2,05 & 1,69 & 3,53 & 10,07 & 13,9 & 3,2 & 0,67 & 28,1 & 25,4 \\
\hline & $\mathrm{Cg} 2(57-80)$ & 3,72 & 378 & 44 & 4 & 4 & 10,7 & 0,10 & 0,99 & 0,65 & 8,83 & 16,95 & 18,7 & 3,0 & 0,91 & 9,8 & 47,2 \\
\hline & Cg3 (80-121) & 3,82 & 387 & 32 & 5 & 4 & 12,4 & 0,08 & 1,76 & 0,36 & 9,14 & 17,60 & 19,8 & 8,6 & 2,07 & 11,8 & 46,2 \\
\hline \multirow{9}{*}{ CUbd } & A11 (0-20) & 3,72 & 198 & 10 & 3 & 2 & 11,4 & 0,15 & 0,87 & 0,53 & 8,52 & 18,26 & 19,8 & 6,8 & 4,20 & 8,0 & 43,0 \\
\hline & A12 (20-45) & 3,89 & 126 & 4 & 23 & 3 & 10,3 & 0,10 & 0,37 & 0,20 & 8,90 & 17,60 & 18,3 & 3,8 & 2,07 & 3,8 & 48,7 \\
\hline & $\mathrm{AB}(45-55)$ & 3,95 & 99 & 3 & 99 & 3 & 10,1 & 0,07 & 0,29 & 0,29 & 8,76 & 16,95 & 17,6 & 1,5 & 1,60 & 3,8 & 49,7 \\
\hline & $\mathrm{BA}(55-72)$ & 3,96 & 117 & 2 & 27 & 3 & 8,6 & 0,09 & 0,42 & 0,19 & 8,47 & 16,95 & 17,7 & 1,4 & 1,80 & 4,2 & 48,0 \\
\hline & B11 (72-85) & 4,06 & 108 & 2 & 171 & 4 & 9,2 & 0,08 & 0,56 & 0,14 & 6,22 & 15,74 & 16,5 & 1,2 & 1,20 & 4,9 & 37,7 \\
\hline & B12 (85-93) & 4,07 & 117 & 2 & 171 & 3 & 6,0 & 0,09 & 0,38 & 0,03 & 6,22 & 15,74 & 16,2 & 1,2 & 0,61 & 3,2 & 38,3 \\
\hline & B21 (93-104) & 4,03 & 126 & 1 & 189 & 2 & 9,1 & 0,11 & 0,39 & 0,32 & 7,47 & 16,95 & 17,8 & 1,2 & 0,60 & 4,8 & 42,0 \\
\hline & B22 (104-10) & 3,98 & 108 & 1 & 135 & 2 & 7,8 & 0,13 & 0,71 & 0,17 & 9,25 & 17,60 & 18,6 & 1,1 & 0,69 & 5,6 & 49,7 \\
\hline & $\mathrm{Cg}(110-170+)$ & 3,94 & 54 & 1 & 9 & 2 & 9,9 & 0,18 & 0,37 & 0,21 & 8,82 & 17,60 & 18,4 & 0,6 & 0,26 & 4,3 & 47,9 \\
\hline \multirow{7}{*}{$\mathrm{LVd}$} & A11 (0-30) & 4,77 & 45 & 128 & 11 & 7 & 16,3 & 1,56 & 8,56 & 2,09 & 0,22 & 9,01 & 21,2 & 14,4 & 2,66 & 57,7 & 1,0 \\
\hline & A12 (30-56) & 3,97 & 81 & 19 & 4 & 2 & 18,3 & 0,42 & 0,90 & 0,10 & 6,86 & 14,61 & 16,0 & 2,3 & 1,32 & 9,1 & 42,9 \\
\hline & $\mathrm{AB}(56-78)$ & 4,04 & 63 & 16 & 10 & 2 & 7,8 & 0,21 & 0,85 & 0,16 & 6,30 & 15,16 & 16,4 & 1,0 & 1,55 & 7,6 & 38,4 \\
\hline & BA $(78-100)$ & 4,17 & 81 & 18 & 23 & 2 & 9,3 & 0,12 & 0,38 & 0,14 & 4,45 & 13,07 & 13,7 & 1,0 & 0,97 & 4,9 & 32,5 \\
\hline & B21 (100-122) & 4,17 & 81 & 12 & 4 & 4 & 11,7 & 0,15 & 0,74 & 0,21 & 4,20 & 13,07 & 14,2 & 1,8 & 0,81 & 7,9 & 29,6 \\
\hline & B22 (122-160) & 4,13 & 54 & 11 & 81 & 2 & 10,6 & 0,16 & 0,68 & 0,07 & 6,23 & 15,16 & 16,1 & 0,8 & 0,02 & 5,9 & 38,7 \\
\hline & $\mathrm{BC}(160-180+)$ & 4,12 & 36 & 9 & 7 & 2 & 11,7 & 0,14 & 0,69 & 0,07 & 6,75 & 15,74 & 16,6 & 1,0 & 0,15 & 5,7 & 40,7 \\
\hline \multirow{6}{*}{$\begin{array}{l}\text { RMC } \\
\text { CUbd }\end{array}$} & A1 (0-5) & 5,50 & 18 & 382 & 13 & 1 & 17,5 & 0,31 & 14,46 & 7,84 & 0,17 & 4,12 & 22,6 & 23,6 & 7,67 & 84,6 & 0,8 \\
\hline & A2 (5-26) & 4,72 & 38 & 257 & 9 & 2 & 10,4 & 0,18 & 10,33 & 6,06 & 0,38 & 6,94 & 23,5 & 16,9 & 3,40 & 70,6 & 1,6 \\
\hline & B1 (26-40) & 3,96 & 63 & 113 & 3 & 2 & 8,3 & 0,09 & 5,11 & 2,83 & 5,07 & 13,07 & 21,1 & 2,6 & 1,62 & 38,2 & 24,0 \\
\hline & $\mathrm{BC}(40-63)$ & 3,92 & 63 & 166 & 5 & 2 & 8,9 & 0,07 & 4,18 & 3,41 & 5,37 & 15,16 & 22,8 & 1,5 & 1,70 & 33,7 & 23,5 \\
\hline & $\operatorname{Cg} 1(63-80)$ & 3,94 & 72 & 167 & 22 & 2 & 15,1 & 0,07 & 3,40 & 2,52 & 4,83 & 13,56 & 19,6 & 1,5 & 1,58 & 30,9 & 24,7 \\
\hline & $\mathrm{Cg} 2(80-120+)$ & 3,98 & 63 & 91 & 10 & 2 & 19,4 & 0,08 & 2,48 & 2,96 & 4,63 & 13,56 & 19,1 & 1,4 & 1,16 & 29,2 & 24,3 \\
\hline \multirow{6}{*}{ RUbd } & A1 (0-15) & 6,38 & 18 & 163 & 13 & 1 & 22,7 & 0,67 & 17,44 & 10,14 & 0,00 & 2,95 & 31,2 & 7,4 & 2,60 & 90,6 & 0,0 \\
\hline & A2 (15-45) & 4,18 & 90 & 26 & 5 & 1 & 11,1 & 0,23 & 5,25 & 4,49 & 4,00 & 13,07 & 23,0 & 3,8 & 3,20 & 43,4 & 17,4 \\
\hline & $\mathrm{AC}(45-62)$ & 3,90 & 45 & 41 & 28 & 1 & 9,1 & 0,13 & 2,01 & 2,03 & 6,78 & 16,95 & 21,1 & 1,8 & 1,61 & 20,0 & 32,1 \\
\hline & $\mathrm{Cg} 1(62-70)$ & 3,90 & 27 & 34 & 26 & 1 & 13,8 & 0,12 & 4,98 & 1,45 & 10,85 & 20,42 & 27,0 & 1,0 & 0,34 & 24,5 & 40,2 \\
\hline & Cg2 (70-83) & 3,97 & 27 & 55 & 5 & 1 & 12,1 & 0,14 & 5,43 & 6,44 & 12,96 & 21,19 & 33,2 & 1,0 & 1,3 & 36,4 & 39,0 \\
\hline & $\mathrm{Cg} 3(83-120+)$ & 4,08 & 27 & 19 & 26 & 1 & 11,0 & 0,15 & 7,49 & 6,79 & 9,10 & 18,96 & 33,4 & 1,3 & 0,56 & 43,4 & 27,2 \\
\hline \multirow{6}{*}{$\mathrm{CHd}$} & A1 (0-15) & 4,48 & 65 & 238 & 8 & 1 & 10,2 & 0,33 & 10,31 & 2,33 & 0,54 & 8,68 & 21,7 & 17,7 & 6,94 & 60,1 & 2,5 \\
\hline & A2 (15-32) & 4,09 & 92 & 115 & 40 & 2 & 9,0 & 0,22 & 4,44 & 4,69 & 2,19 & 10,45 & 19,8 & 6,0 & 4,66 & 47,5 & 11,1 \\
\hline & $\mathrm{AB}(32-50)$ & 3,81 & 112 & 22 & 39 & 3 & 12,0 & 0,24 & 1,52 & 1,46 & 4,64 & 13,56 & 16,8 & 3,5 & 2,70 & 19,4 & 27,6 \\
\hline & B1 (50-94) & 3,74 & 83 & 76 & 26 & 3 & 9,1 & 0,08 & 1,15 & 0,65 & 5,94 & 14,61 & 16,5 & 2,0 & 3,09 & 11,7 & 36,0 \\
\hline & B21 (94-100) & 3,85 & 77 & 28 & 50 & 2 & 11,9 & 0,06 & 1,05 & 0,78 & 5,32 & 14,07 & 16,0 & 1,5 & 2,11 & 12,1 & 33,0 \\
\hline & B22 (100-120+) & 3,95 & 52 & 16 & 11 & 2 & 14,5 & 0,06 & 0,90 & 0,69 & 4,61 & 11,68 & 13,3 & 1,0 & 2,20 & 12,6 & 34,7 \\
\hline
\end{tabular}


Tabela 3. Valores médios de $\mathrm{pH}, \mathrm{P}, \mathrm{K}^{+}, \mathrm{Ca}^{+2}, \mathrm{Mg}^{+2}, \mathrm{Al}^{+3}, \mathrm{H}^{+}+\mathrm{Al}^{+3}, \mathrm{C}, \mathrm{CTC}, \mathrm{V} \%$ e $\mathrm{m} \%$, por classe de solo, nas profundidades de 0-5 cm, 5-10 cm, 10-15 cm e 15-20 cm, sob as populações naturais de Maytenus ilicifolia.

\begin{tabular}{|c|c|c|c|c|c|c|c|c|c|c|c|c|}
\hline \multirow{2}{*}{ População/Solo } & \multirow{2}{*}{$\begin{array}{l}\text { Prof. } \\
\text { (cm) }\end{array}$} & \multirow{2}{*}{$\underset{\mathrm{CaCl}_{2}}{\mathbf{p H}}$} & $\mathbf{K}$ & $\mathrm{Ca}$ & Mg & Al & $\mathbf{H}+\mathbf{A l}$ & CTC & \multirow{2}{*}{$\begin{array}{c}\mathbf{P} \\
\left(\mathbf{m g . d m}^{-3}\right)\end{array}$} & C & $\mathbf{V}$ & $\mathbf{m}$ \\
\hline & & & \multicolumn{6}{|c|}{$\left(\mathrm{cmol}_{\mathrm{c}} \cdot \mathrm{dm}^{-3}\right)$} & & \multicolumn{3}{|c|}{$(\%)$} \\
\hline \multirow{4}{*}{$\begin{array}{l}\text { Manasa } \\
\text { RLh }\end{array}$} & $0-5$ & 4,37 & 0,40 & 2,27 & 0,85 & 1,65 & 11,09 & 14,61 & 12,7 & 7,24 & 24,6 & 11,3 \\
\hline & $5-10$ & 4,45 & 0,32 & 1,16 & 0,47 & 1,74 & 10,70 & 12,65 & 18,0 & 7,20 & 15,5 & 13,8 \\
\hline & $10-15$ & 4,39 & 0,29 & 1,04 & 0,38 & 1,63 & 10,97 & 12,68 & 10,1 & 7,37 & 14,3 & 12,9 \\
\hline & $15-20$ & 4,41 & 0,27 & 0,93 & 0,29 & 1,65 & 10,36 & 11,85 & 9,1 & 7,28 & 13,6 & 13,9 \\
\hline \multirow{4}{*}{$\begin{array}{l}\text { Rureco } \\
\text { CXbd }\end{array}$} & $0-5$ & 4,28 & 0,60 & 2,25 & 0,99 & 1,70 & 9,57 & 13,41 & 4,4 & 3,02 & 28,6 & 12,6 \\
\hline & $5-10$ & 4,24 & 0,45 & 1,48 & 0,45 & 2,00 & 9,67 & 12,05 & 2,0 & 2,55 & 19,8 & 16,6 \\
\hline & $10-15$ & 4,21 & 0,34 & 1,09 & 0,28 & 1,99 & 9,40 & 11,11 & 2,4 & 2,58 & 15,4 & 17,9 \\
\hline & $15-20$ & 4,23 & 0,26 & 0,79 & 0,45 & 1,96 & 9,29 & 10,79 & 2,2 & 2,25 & 13,9 & 18,2 \\
\hline \multirow{4}{*}{$\begin{array}{l}\text { Flona } \\
\text { GXbd-fs }\end{array}$} & $0-5$ & 4,64 & 0,54 & 7,48 & 5,05 & 0,27 & 5,78 & 18,81 & 9,1 & 2,57 & 69,0 & 1,4 \\
\hline & $5-10$ & 4,53 & 0,36 & 6,83 & 3,43 & 0,53 & 6,05 & 16,67 & 6,9 & 2,58 & 63,9 & 3,2 \\
\hline & $10-15$ & 4,50 & 0,33 & 8,13 & 2,99 & 1,03 & 5,80 & 17,25 & 5,5 & 2,04 & 63,5 & 6,0 \\
\hline & $15-20$ & 4,49 & 0,31 & 5,27 & 3,82 & 0,52 & 5,50 & 14,90 & 5,1 & 1,80 & 63,3 & 3,5 \\
\hline \multirow{4}{*}{ GXbd } & $0-5$ & 4,19 & 0,40 & 5,43 & 4,56 & 0,72 & 8,08 & 18,47 & 10,5 & 3,00 & 35,2 & 3,9 \\
\hline & $5-10$ & 4,22 & 0,39 & 7,03 & 3,88 & 1,00 & 9,17 & 20,47 & 7,9 & 2,78 & 54,9 & 4,9 \\
\hline & $10-15$ & 4,19 & 0,41 & 7,57 & 3,52 & 1,16 & 9,57 & 21,07 & 6,8 & 2,56 & 54,4 & 5,5 \\
\hline & $15-20$ & 4,06 & 0,36 & 6,53 & 2,52 & 1,37 & 9,19 & 18,60 & 5,4 & 1,97 & 50,7 & 7,4 \\
\hline \multirow{4}{*}{ CUbd } & $0-5$ & 3,50 & 0,16 & 2,73 & 0,97 & 6,01 & 23,58 & 27,44 & 10,0 & 3,20 & 15,0 & 21,9 \\
\hline & $5-10$ & 3,50 & 0,13 & 1,63 & 0,88 & 6,99 & 22,16 & 24,80 & 7,8 & 2,91 & 11,6 & 28,2 \\
\hline & $10-15$ & 3,47 & 0,10 & 1,33 & 0,62 & 7,28 & 18,76 & 20,81 & 6,8 & 2,59 & 9,6 & 35,0 \\
\hline & $15-20$ & 3,48 & 0,09 & 1,12 & 0,44 & 7,11 & 21,06 & 22,71 & 5,1 & 2,71 & 7,9 & 31,3 \\
\hline \multirow{4}{*}{ LVAd } & $0-5$ & 4,94 & 2,34 & 7,81 & 1,41 & 0,14 & 5,76 & 15,41 & 22,9 & 2,25 & 66,7 & 0,9 \\
\hline & $5-10$ & 4,65 & 1,92 & 3,42 & 0,72 & 0,43 & 8,36 & 14,42 & 17,0 & 2,76 & 42,0 & 3,0 \\
\hline & $10-15$ & 4,03 & 1,26 & 2,96 & 0,99 & 2,84 & 11,68 & 16,89 & 10,7 & 2,49 & 30,9 & 16,8 \\
\hline & $15-20$ & 3,85 & 1,98 & 1,74 & 1,65 & 7,22 & 14,07 & 19,44 & 8,1 & 2,46 & 27,6 & 37,1 \\
\hline \multirow{4}{*}{$\begin{array}{l}\text { RMC } \\
\text { CUbd }\end{array}$} & $0-5$ & 5,53 & 0,32 & 14,17 & 5,58 & 0,13 & 4,29 & 24,36 & 36,0 & 6,32 & 82,4 & 0,5 \\
\hline & $5-10$ & 4,81 & 0,24 & 10,80 & 5,35 & 0,28 & 5,77 & 22,16 & 19,5 & 4,52 & 73,9 & 1,3 \\
\hline & $10-15$ & 4,50 & 0,20 & 8,91 & 6,30 & 0,64 & 6,82 & 22,23 & 14,2 & 3,57 & 69,1 & 2,9 \\
\hline & $15-20$ & 4,22 & 0,16 & 7,82 & 6,45 & 1,50 & 8,05 & 22,48 & 9,7 & 2,97 & 64,0 & 6,7 \\
\hline \multirow{4}{*}{ RUbd } & $0-5$ & 6,20 & 0,63 & 15,74 & 8,09 & 0,07 & 2,51 & 26,97 & 11,9 & 4,35 & 90,7 & 0,3 \\
\hline & $5-10$ & 6,38 & 0,65 & 15,49 & 8,50 & 0,03 & 2,32 & 26,96 & 12,9 & 4,84 & 91,4 & 0,1 \\
\hline & $10-15$ & 6,31 & 0,68 & 13,37 & 8,71 & 0,03 & 2,84 & 28,44 & 10,5 & 3,77 & 75,0 & 0,1 \\
\hline & $15-20$ & 6,06 & 0,52 & 10,35 & 9,03 & 0,04 & 3,43 & 23,33 & 9,4 & 3,80 & 85,3 & 0,2 \\
\hline \multirow{4}{*}{ CHd } & $0-5$ & 4,40 & 0,35 & 8,47 & 4,13 & 1,03 & 9,98 & 22,93 & 23,6 & 6,19 & 56,4 & 4,5 \\
\hline & $5-10$ & 4,28 & 0,26 & 5,50 & 2,28 & 1,60 & 11,48 & 19,52 & 13,8 & 6,02 & 44,3 & 8,2 \\
\hline & $10-15$ & 4,11 & 0,27 & 4,51 & 2,70 & 2,15 & 11,47 & 18,95 & 10,6 & 4,63 & 39,2 & 11,3 \\
\hline & $15-20$ & 3,97 & 0,22 & 2,92 & 2,19 & 2,64 & 11,96 & 17,29 & 7,1 & 6,17 & 31,8 & 15,3 \\
\hline
\end{tabular}


Tabela 4. Características granulométricas dos solos das populações naturais de M. ilicifolia.

\begin{tabular}{|c|c|c|c|c|c|c|}
\hline \multirow{2}{*}{ População/Solo } & \multirow{2}{*}{$\begin{array}{l}\text { Horizonte } \\
\text { (cm) }\end{array}$} & Areia grossa & Areia fina & Areia & Silte & Argila \\
\hline & & \multicolumn{5}{|c|}{ (\%) } \\
\hline $\begin{array}{l}\text { Manasa } \\
\text { RLh }\end{array}$ & Ap (0-19) & 15 & 14 & 29 & 57 & 14 \\
\hline \multirow{5}{*}{$\begin{array}{l}\text { Rureco } \\
\text { CXbd }\end{array}$} & A1 (0-45) & 2 & 2 & 4 & 27 & 69 \\
\hline & A2 (45-90) & 2 & 2 & 4 & 24 & 72 \\
\hline & $\mathrm{AB}(90-120)$ & 2 & 1 & 3 & 22 & 75 \\
\hline & BA (120-150) & 3 & 1 & 4 & 23 & 73 \\
\hline & $\mathrm{Bi}(150-180+)$ & 3 & 1 & 4 & 26 & 70 \\
\hline \multirow{5}{*}{$\begin{array}{l}\text { Flona } \\
\text { GXbd-fs }\end{array}$} & Apb (0-20) & 5 & 40 & 45 & 39 & 16 \\
\hline & A1 (20-38) & 2 & 35 & 37 & 46 & 17 \\
\hline & Cg1 (38-57) & 1 & 42 & 43 & 35 & 22 \\
\hline & Cg2 (57-80) & 0 & 21 & 21 & 48 & 31 \\
\hline & Cg3 (80-121) & 0 & 11 & 11 & 42 & 47 \\
\hline \multirow{9}{*}{ CUbd } & A11 (0-20) & 2 & 13 & 15 & 40 & 45 \\
\hline & A12 (20-45) & 0 & 14 & 14 & 44 & 42 \\
\hline & $\mathrm{AB}(45-55)$ & 0 & 12 & 12 & 40 & 48 \\
\hline & $\mathrm{BA}(55-72)$ & 1 & 12 & 13 & 34 & 53 \\
\hline & B11 (72-85) & 0 & 11 & 11 & 36 & 53 \\
\hline & B12 (85-93) & 0 & 13 & 13 & 38 & 49 \\
\hline & B21 (93-104) & 0 & 11 & 11 & 40 & 49 \\
\hline & B22 (104-10) & 0 & 15 & 15 & 37 & 48 \\
\hline & $\mathrm{Cg}(110-170+)$ & 0 & 20 & 20 & 44 & 36 \\
\hline \multirow{7}{*}{ LVAd } & A11 (0-30) & 1 & 14 & 15 & 42 & 43 \\
\hline & A12 (30-56) & 1 & 15 & 16 & 34 & 50 \\
\hline & $\mathrm{AB}(56-78)$ & 0 & 16 & 16 & 31 & 53 \\
\hline & BA (78-100) & 1 & 14 & 15 & 37 & 48 \\
\hline & B21 (100-122) & 0 & 16 & 16 & 37 & 47 \\
\hline & B22 (122-160) & 1 & 16 & 17 & 33 & 50 \\
\hline & BC (160-180+) & 1 & 14 & 15 & 48 & 37 \\
\hline \multirow{6}{*}{$\begin{array}{l}\text { RMC } \\
\text { CUbd }\end{array}$} & A1 (0-5) & 2 & 9 & 11 & 65 & 24 \\
\hline & A2 (5-26) & 1 & 15 & 16 & 50 & 34 \\
\hline & B1 (26-40) & 1 & 23 & 24 & 42 & 34 \\
\hline & BC (40-63) & 2 & 20 & 22 & 48 & 30 \\
\hline & Cg1 (63-80) & 1 & 10 & 11 & 38 & 51 \\
\hline & Cg2 (80-120+) & 1 & 12 & 13 & 34 & 53 \\
\hline \multirow{6}{*}{ RUbd } & A1 $(0-15)$ & 5 & 9 & 14 & 47 & 39 \\
\hline & A2 (15-45) & 7 & 16 & 23 & 35 & 42 \\
\hline & $\mathrm{AC}(45-62)$ & 12 & 18 & 30 & 28 & 42 \\
\hline & Cg1 (62-70) & 5 & 19 & 24 & 31 & 45 \\
\hline & Cg2 (70-83) & 5 & 17 & 22 & 35 & 43 \\
\hline & $\mathrm{Cg} 3(83-120+)$ & 8 & 22 & 30 & 33 & 37 \\
\hline \multirow{6}{*}{ CHd } & A1 $(0-15)$ & 3 & 11 & 14 & 52 & 34 \\
\hline & A2 (15-32) & 3 & 10 & 13 & 42 & 45 \\
\hline & $\mathrm{AB}(32-50)$ & 4 & 17 & 21 & 32 & 47 \\
\hline & B1 (50-94) & 6 & 16 & 22 & 26 & 52 \\
\hline & B21 (94-100) & 8 & 15 & 23 & 22 & 55 \\
\hline & B22 (100-120+) & 13 & 12 & 25 & 23 & 52 \\
\hline
\end{tabular}


Korndörfer et al. (1999a) comentam que para solos com os mesmos teores de argila, os teores de $\mathrm{Si}$ solúvel podem ser maiores nos solos com horizonte B textural do que nos solos com B latossólico. O que se observa nos perfis analisados neste trabalho são teores relativamente mais elevados de $\mathrm{Si}$, nos Neossolos e solos com horizonte B câmbico, fato relacionado ao menor grau de intemperismo destes solos. Também se observam teores de Si mais elevados nos solos da RMC, o que pode estar relacionado tanto ao menor grau de intemperismo quanto ao material de origem destes solos, mais ricos em silicatos.

Além do quartzo, as principais reservas de $\mathrm{Si}$ dos solos são os minerais aluminossilicatados, como feldspatos alcalinos e plagioclásio, que com o processo de intemperismo contribuem significativamente com o conteúdo de $\mathrm{Al}$ e $\mathrm{K}$ nos solos, além do próprio $\mathrm{Si}$ (Exley, 1998). De acordo com Mineropar (2005), os materiais de origem dos solos avaliados neste estudo apresentam ambos $\mathrm{Al}$ e $\mathrm{K}$ em sua composição, com menor quantidade de feldspato em relação a plagioclásio nos solos das populações de Guarapuava (Manasa e Rureco). Estas diferenças podem ser constatadas quando se observa os teores trocáveis de $\mathrm{K} \mathrm{e} \mathrm{Al}$ ao longo dos perfis, com incremento dos teores de $\mathrm{Al}$ em profundidade nos solos do segundo e terceiro planaltos. O Si também é citado como um elemento regulador da disponibilidade de $\mathrm{P}$ no solo, já que ambos ocupam os mesmos sítios de adsorção nas superfícies de óxidos de Fe (KabataPendias \& Pendias, 1992). Provavelmente, os elevados teores de P estão sendo disponibilizados em função da ocupação preferencial do Si nestes sítios de troca.

Quanto aos micronutrientes disponíveis nos solos (Tabela 2), chamam a atenção os elevados teores de Fe e Mn sob a população Flona, em particular nos solos GXbd e CUbd, e os teores de Mn, sob o solo CUbd da população RMC. Estes valores estão associados ao fato destes solos apresentarem grande flutuação no regime hídrico, o que promove reações de redução ao longo do perfil, aumentando a solubilidade destes dois elementos. Os teores de $\mathrm{Cu}$ foram os que menos variaram entre as classes de solos e entre os horizontes, confirmando o fato de que a maior parte do conteúdo deste elemento originase da deposição de matéria orgânica nos horizontes superficiais (Kabata-Pendias \& Pendias, 1992).

\section{Massa específica foliar e composição fitoquímica}

Na Tabela 5, encontram-se os dados médios de massa, área foliar e massa específica foliar, obtidos para as quatro populações avaliadas.

Tabela 5. Massa seca foliar, área foliar e massa específica foliar de quatro populações naturais de Maytenus ilicifolia (média de dez repetições).

\begin{tabular}{lccc}
\hline $\begin{array}{l}\text { População / } \\
\text { Ambiente lumínico }\end{array}$ & $\begin{array}{c}\text { Massa } \\
(\mathbf{g})\end{array}$ & $\begin{array}{c}\text { Área foliar } \\
\left.\mathbf{( c m}^{2}\right)\end{array}$ & $\begin{array}{c}\text { Massa específica } \\
\text { foliar } \\
\left(\mathbf{m g . c m}^{-2}\right)\end{array}$ \\
\hline Manasa (pleno sol) & $6,26 \quad \mathrm{~b}$ & $326,0 \mathrm{c}$ & $19,38 \mathrm{a}$ \\
Rureco (meia sombra) & $7,32 \mathrm{ab}$ & $571,7 \mathrm{~b}$ & $13,08 \mathrm{~b}$ \\
Flona (sombra) & 9,76 a & $842,1 \mathrm{a}$ & $11,97 \mathrm{~b}$ \\
RMC (sombra) & $9,61 \quad \mathrm{a}$ & $939,0 \mathrm{a}$ & $10,94 \mathrm{~b}$ \\
\hline
\end{tabular}

Médias seguidas pela mesma letra não diferem significativamente entre si, pelo teste de Duncan ao nível de $5 \%$ de probabilidade.

Observou-se a influência do ambiente lumínico no acúmulo de biomassa foliar. Menores valores de PAR no verão resultaram em menor massa específica foliar para plantas das populações Rureco, Flona e RMC. Sabe-se que o tamanho da folha é determinado por um complexo de fatores ambientais e endógenos, e a quantidade de luz, mais do que sua qualidade, pode influenciar a estrutura da folha, o crescimento da planta e a alocação de biomassa (Kurepin et al., 2006). O menor valor de massa específica para as plantas de sombra está relacionado à adaptação de uma mesma espécie a ambientes com menor disponibilidade de luz, através da diminuição da capacidade fotossintética e menor alocação de compostos à base de carbono (Cipollini, 2004).

No caso de $M$. ilicifolia, a maior quantidade de luz proporcionou um incremento da massa específica proporcional à produção de fenóis totais, cujos teores podem ser encontrados na Tabela 6 . Estas variáveis apresentaram uma alta correlação $\left(\mathrm{r}^{2}=0,73\right.$, Tabela 8 ), confirmando resultados obtidos anteriormente por Radomski et al., (2004a), cujo trabalho revelou, para uma mesma população de $M$. ilicifolia, a influência da maior luminosidade sobre a alocação de biomassa e síntese de fenóis. 
Tabela 6. Teores foliares de lignina, fenóis totais, fenóis não-tanantes, e taninos, em quatro populações naturais de Maytenus ilicifolia (média de dez repetições).

\begin{tabular}{lcccc}
\hline População & Lignina & $\begin{array}{c}\text { Fenóis } \\
\text { totais }\end{array}$ & $\begin{array}{c}\text { Fenóis não } \\
\text { tanantes }\end{array}$ & $\begin{array}{c}\text { Taninos } \\
(\%)\end{array}$ \\
\hline Manasa & $21,5 \mathrm{~b}$ & $19,3 \mathrm{a}$ & $6,6 \mathrm{a}$ & $12,7 \mathrm{a}$ \\
Rureco & $25,6 \mathrm{a}$ & $8,6 \mathrm{~b}$ & $5,1 \mathrm{~b}$ & $3,5 \mathrm{~b}$ \\
Flona & $26,6 \mathrm{a}$ & $9,9 \mathrm{~b}$ & $4,7 \mathrm{~b}$ & $5,2 \mathrm{~b}$ \\
RMC & $24,7 \mathrm{a}$ & $8,0 \mathrm{~b}$ & $4,2 \mathrm{~b}$ & $3,8 \mathrm{~b}$ \\
\hline
\end{tabular}

Médias seguidas pela mesma letra não diferem significativamente entre si, pelo teste de Duncan ao nível de 5\% de probabilidade.

Os teores de lignina (Tabela 6) foram maiores nos ambientes de sombra, o que parece compensar a menor síntese de fenóis. Além do papel deterrente, ou seja, de inibidor da herbivoria, os fenóis também protegem as plantas contra raios UV, via ativação da enzima fenilalanina amônia-liase pela luz (Goto et al., 2003; Taiz \& Zeiger, 2004); em ambientes de sombra, a incidência de radiação UV é menor (Larcher, 1986), portanto, a enzima responsável pela síntese de fenóis é menos estimulada e os carboidratos, produtos da fotossíntese, seguem preferencialmente a via de síntese da lignina.

Em relação aos elementos minerais, cujos teores encontram-se na Tabela 7, $\mathrm{N}$ e $\mathrm{K}$ foram os que mais se relacionaram com as diferentes condições de luminosidade, sendo seus teores significativamente inferiores nas plantas crescendo a pleno sol. No caso das populações Rureco, Flona e RMC, a baixa luminosidade, combinada com alto suprimento de nutrientes nas camadas superiores da maior parte dos solos, deve contribuir para a produção de uma alta concentração de aminoácidos e menor concentração de compostos à base de carbono. Este fato corrobora a teoria do balanço $\mathrm{C} / \mathrm{N}$ nas plantas, conforme comentado por diversos autores (Janzen, 1974; Coley et al., 1985; Varanda et al., 1998), tendo-se verificado, apenas no caso dos fenóis não tanantes, uma correlação negativa com os teores de $\mathrm{Ca}$ e Mg do solo (Tabela 8).

Tabela 7. Teores foliares dos elementos minerais $\mathrm{N}, \mathrm{P}, \mathrm{K}, \mathrm{Ca}, \mathrm{Mg}, \mathrm{Si}, \mathrm{Fe}, \mathrm{Mn}, \mathrm{Cu}, \mathrm{Zn}$, e Al, em quatro populações naturais de Maytenus ilicifolia (média de dez repetições).

\begin{tabular}{|c|c|c|c|c|c|c|c|c|c|c|c|}
\hline \multirow{2}{*}{ População } & $\mathbf{N}$ & $\mathbf{P}$ & $\mathbf{K}$ & $\mathrm{Ca}$ & Mg & $\mathbf{S i}$ & $\mathrm{Fe}$ & Mn & $\mathrm{Cu}$ & Zn & Al \\
\hline & \multicolumn{6}{|c|}{$\left(\mathrm{g} \cdot \mathrm{kg}^{-1}\right)$} & \multicolumn{5}{|c|}{$\left(\mathrm{mg} \cdot \mathrm{kg}^{-1}\right)$} \\
\hline Manasa & $17,7 \mathrm{c}$ & $0,94 \mathrm{a}$ & $8,3 \mathrm{c}$ & $3,2 \mathrm{c}$ & $2,4 \mathrm{~b}$ & $3,50 \mathrm{a}$ & $68,1 \mathrm{~b}$ & $54,3 \mathrm{~b}$ & $5,5 \mathrm{~b}$ & $9,3 \mathrm{~b}$ & $54,7 \mathrm{~b}$ \\
\hline Rureco & $24,3 \mathrm{a}$ & $1,11 \mathrm{a}$ & $15,0 \mathrm{a}$ & $4,2 \mathrm{c}$ & $4,0 \mathrm{a}$ & $3,50 \mathrm{a}$ & $104,6 \mathrm{a}$ & $83,0 \mathrm{ab}$ & 8,1 a & $10,7 \mathrm{~b}$ & 83,3 a \\
\hline Flona & $19,9 \mathrm{~b}$ & $1,20 \mathrm{a}$ & $13,6 a b$ & $7,3 \mathrm{~b}$ & $2,9 \mathrm{~b}$ & $3,39 \mathrm{a}$ & $67,1 \mathrm{~b}$ & $93,3 \mathrm{a}$ & $5,7 \mathrm{~b}$ & $15,4 \mathrm{a}$ & $39,8 \mathrm{~b}$ \\
\hline $\mathrm{RMC}$ & $18,0 \mathrm{c}$ & $1,09 \mathrm{a}$ & $12,4 a b$ & $9,8 \mathrm{a}$ & $4,3 \mathrm{a}$ & $3,69 \mathrm{a}$ & $78,7 \mathrm{~b}$ & $73,6 \mathrm{ab}$ & $5,5 \mathrm{~b}$ & $11,6 \mathrm{ab}$ & $78,0 \mathrm{a}$ \\
\hline
\end{tabular}

Médias seguidas pela mesma letra não diferem significativamente entre si, pelo teste de Duncan ao nível de 5\% de probabilidade.

Tabela 8. Matriz de correlação entre variáveis fitoquímicas e características dos solos para as populações naturais de Maytenus ilicifolia.

\begin{tabular}{lcccccccccccccc}
\hline & Massa & Área foliar & $\begin{array}{c}\text { Massa } \\
\text { específica }\end{array}$ & $\mathbf{N}$ & $\mathbf{P}$ & $\mathbf{K}$ & $\mathbf{C a}$ & $\mathbf{M g}$ & $\mathbf{F e}$ & $\mathbf{M n}$ & $\mathbf{C u}$ & $\mathbf{Z n}$ & $\mathbf{A l}$ & $\mathbf{S i}$ \\
\hline Massa & 1,00 & 0,72 & $-0,04$ & $-0,24$ & 0,19 & $-0,16$ & 0,17 & $-0,20$ & $-0,32$ & $-0,08$ & $-0,28$ & 0,02 & $-0,35$ & $-0,15$ \\
Área folilar & 0,72 & 1,00 & $-0,64$ & $-0,10$ & 0,22 & 0,13 & 0,36 & 0,09 & $-0,07$ & $-0,01$ & $-0,47$ & 0,21 & $-0,15$ & 0,27 \\
Massa & & & & & & & & & & & & & & \\
específica & $-0,04$ & $-0,64$ & 1,00 & $-0,24$ & $-0,11$ & $-0,58$ & $-0,45$ & $-0,42$ & $-0,25$ & $-0,28$ & 0,25 & $-0,28$ & $-0,23$ & $-0,33$ \\
N & $-0,24$ & $-0,10$ & $-0,24$ & 1,00 & $-0,01$ & 0,49 & $-0,41$ & 0,29 & 0,49 & 0,31 & 0,31 & 0,00 & 0,22 & 0,18 \\
P & 0,19 & 0,22 & $-0,11$ & $-0,01$ & 1,00 & $-0,05$ & $-0,07$ & $-0,12$ & $-0,18$ & 0,13 & 0,06 & $-0,10$ & $-0,15$ & 0,19 \\
K & $-0,16$ & 0,13 & $-0,58$ & 0,49 & $-0,05$ & 1,00 & 0,03 & 0,20 & 0,39 & 0,28 & 0,35 & 0,32 & 0,23 & 0,03 \\
Ca & 0,17 & 0,36 & $-0,45$ & $-0,41$ & $-0,07$ & 0,03 & 1,00 & 0,32 & $-0,17$ & 0,27 & $-0,36$ & 0,43 & $-0,01$ & $-0,11$ \\
Mg & $-0,20$ & 0,09 & $-0,42$ & 0,29 & $-0,12$ & 0,20 & 0,32 & 1,00 & 0,42 & 0,26 & 0,00 & 0,08 & 0,54 & 0,15 \\
\hline
\end{tabular}


Tabela 8. Continuação.

\begin{tabular}{|c|c|c|c|c|c|c|c|c|c|c|c|c|c|c|}
\hline & Massa & Área foliar & $\begin{array}{c}\text { Massa } \\
\text { específica }\end{array}$ & $\mathbf{N}$ & $\mathbf{P}$ & $\mathbf{K}$ & $\mathrm{Ca}$ & Mg & $\mathrm{Fe}$ & Mn & $\mathbf{C u}$ & Zn & Al & $\mathbf{S i}$ \\
\hline $\mathrm{Fe}$ & $-0,32$ & $-0,07$ & $-0,25$ & 0,49 & $-0,18$ & 0,39 & $-0,17$ & 0,42 & 1,00 & 0,03 & 0,18 & 0,01 & 0,59 & 0,18 \\
\hline $\mathrm{Mn}$ & $-0,08$ & $-0,01$ & $-0,28$ & 0,31 & 0,13 & 0,28 & 0,27 & 0,26 & 0,03 & 1,00 & 0,16 & 0,36 & 0,13 & 0,03 \\
\hline $\mathrm{Cu}$ & $-0,28$ & $-0,47$ & 0,25 & 0,31 & 0,06 & 0,35 & $-0,36$ & 0,00 & 0,18 & 0,16 & 1,00 & $-0,14$ & 0,31 & $-0,16$ \\
\hline $\mathrm{Zn}$ & 0,02 & 0,21 & $-0,28$ & 0,00 & $-0,10$ & 0,32 & 0,43 & 0,08 & 0,01 & 0,36 & $-0,14$ & 1,00 & $-0,24$ & $-0,19$ \\
\hline $\mathrm{Al}$ & $-0,35$ & $-0,15$ & $-0,23$ & 0,22 & $-0,15$ & 0,23 & $-0,01$ & 0,54 & 0,59 & 0,13 & 0,31 & $-0,24$ & 1,00 & 0,18 \\
\hline $\mathrm{Si}$ & $-0,15$ & 0,27 & $-0,33$ & 0,18 & 0,19 & 0,03 & $-0,11$ & 0,15 & 0,18 & 0,03 & $-0,16$ & $-0,19$ & 0,18 & 1,00 \\
\hline Lignina & $-0,23$ & 0,18 & $-0,61$ & 0,44 & $-0,04$ & 0,59 & 0,17 & 0,28 & 0,28 & 0,38 & $-0,06$ & 0,38 & $-0,04$ & 0,26 \\
\hline Fenóis T. & $-0,13$ & $-0,43$ & 0,73 & $-0,26$ & 0,02 & $-0,56$ & $-0,50$ & $-0,54$ & $-0,26$ & $-0,42$ & $-0,03$ & $-0,23$ & $-0,27$ & $-0,05$ \\
\hline Fenóis Nt & $-0,15$ & $-0,42$ & 0,57 & $-0,02$ & 0,03 & $-0,44$ & $-0,63$ & $-0,43$ & $-0,07$ & $-0,29$ & 0,22 & $-0,39$ & $-0,07$ & 0,06 \\
\hline Tanantes & $-0,10$ & $-0,36$ & 0,65 & $-0,28$ & 0,02 & $-0,49$ & $-0,37$ & $-0,47$ & $-0,27$ & $-0,38$ & $-0,09$ & $-0,15$ & $-0,27$ & $-0,07$ \\
\hline pH 0-5 & 0,10 & $-0,06$ & 0,14 & $-0,53$ & $-0,21$ & $-0,12$ & 0,41 & $-0,01$ & $-0,16$ & $-0,33$ & 0,01 & $-0,07$ & 0,08 & $-0,50$ \\
\hline pH 0-10 & 0,09 & $-0,11$ & 0,19 & $-0,51$ & $-0,22$ & $-0,16$ & 0,35 & $-0,02$ & $-0,17$ & $-0,39$ & 0,01 & $-0,10$ & 0,06 & $-0,55$ \\
\hline pH 0-15 & 0,11 & $-0,11$ & 0,20 & $-0,43$ & $-0,22$ & $-0,16$ & 0,28 & $-0,04$ & $-0,15$ & $-0,46$ & 0,01 & $-0,13$ & 0,03 & $-0,59$ \\
\hline pH 0-20 & 0,11 & $-0,14$ & 0,24 & $-0,37$ & $-0,22$ & $-0,17$ & 0,17 & $-0,06$ & $-0,12$ & $-0,51$ & 0,03 & $-0,19$ & 0,02 & $-0,60$ \\
\hline K 0-5 & $-0,03$ & $-0,19$ & 0,21 & $-0,08$ & $-0,14$ & 0,11 & 0,01 & $-0,10$ & $-0,02$ & $-0,08$ & 0,26 & 0,46 & $-0,06$ & $-0,30$ \\
\hline K $0-10$ & $-0,01$ & $-0,17$ & 0,21 & $-0,11$ & $-0,14$ & 0,10 & 0,04 & $-0,10$ & $-0,04$ & $-0,09$ & 0,22 & 0,48 & $-0,10$ & $-0,32$ \\
\hline K $0-15$ & $-0,04$ & $-0,20$ & 0,22 & $-0,09$ & $-0,15$ & 0,11 & 0,02 & $-0,15$ & $-0,02$ & $-0,18$ & 0,21 & 0,49 & $-0,11$ & $-0,38$ \\
\hline K 0-20 & $-0,01$ & $-0,18$ & 0,23 & $-0,16$ & $-0,13$ & 0,06 & 0,07 & $-0,17$ & $-0,09$ & $-0,15$ & 0,14 & 0,52 & $-0,19$ & $-0,37$ \\
\hline $\mathrm{Ca} 0-5$ & 0,32 & 0,29 & $-0,09$ & $-0,65$ & $-0,05$ & $-0,20$ & 0,62 & 0,07 & $-0,35$ & $-0,08$ & $-0,17$ & 0,04 & $-0,01$ & $-0,22$ \\
\hline $\mathrm{Ca} 0-10$ & 0,31 & 0,31 & $-0,16$ & $-0,63$ & $-0,06$ & $-0,14$ & 0,70 & 0,10 & $-0,29$ & $-0,10$ & $-0,26$ & 0,09 & $-0,07$ & $-0,30$ \\
\hline $\mathrm{Ca} 0-15$ & 0,30 & 0,31 & $-0,21$ & $-0,57$ & $-0,06$ & $-0,08$ & 0,70 & 0,02 & $-0,21$ & $-0,14$ & $-0,31$ & 0,15 & $-0,18$ & $-0,37$ \\
\hline $\mathrm{Ca} 0-20$ & 0,26 & 0,27 & $-0,21$ & $-0,54$ & $-0,04$ & $-0,05$ & 0,70 & $-0,01$ & $-0,23$ & $-0,11$ & $-0,32$ & 0,19 & $-0,22$ & $-0,41$ \\
\hline Mg 0-5 & 0,21 & 0,28 & $-0,27$ & $-0,59$ & $-0,10$ & $-0,02$ & 0,61 & 0,10 & $-0,32$ & $-0,05$ & $-0,10$ & $-0,03$ & 0,06 & $-0,26$ \\
\hline Mg 0-10 & 0,25 & 0,28 & $-0,26$ & $-0,58$ & $-0,08$ & $-0,02$ & 0,67 & 0,07 & $-0,29$ & $-0,07$ & $-0,17$ & 0,02 & $-0,02$ & $-0,37$ \\
\hline Mg 0-15 & 0,23 & 0,24 & $-0,22$ & $-0,54$ & $-0,07$ & $-0,04$ & 0,68 & 0,05 & $-0,30$ & $-0,03$ & $-0,20$ & 0,11 & $-0,05$ & $-0,41$ \\
\hline Mg 0-20 & 0,29 & 0,24 & $-0,14$ & $-0,55$ & $-0,08$ & $-0,11$ & 0,69 & 0,04 & $-0,28$ & $-0,06$ & $-0,20$ & 0,08 & $-0,06$ & $-0,48$ \\
\hline P 0-5 & 0,09 & 0,28 & $-0,19$ & $-0,58$ & $-0,09$ & $-0,20$ & 0,60 & 0,23 & $-0,23$ & 0,10 & $-0,32$ & 0,13 & 0,09 & 0,18 \\
\hline P $0-10$ & 0,14 & 0,29 & $-0,13$ & $-0,64$ & $-0,09$ & $-0,27$ & 0,61 & 0,20 & $-0,24$ & 0,04 & $-0,38$ & 0,14 & 0,04 & 0,14 \\
\hline P $0-15$ & 0,17 & 0,30 & $-0,06$ & $-0,69$ & $-0,09$ & $-0,36$ & 0,60 & 0,09 & $-0,25$ & $-0,04$ & $-0,46$ & 0,18 & $-0,06$ & 0,11 \\
\hline P $0-20$ & 0,18 & 0,26 & 0,04 & $-0,75$ & $-0,08$ & $-0,44$ & 0,53 & $-0,04$ & $-0,28$ & $-0,18$ & $-0,47$ & 0,13 & $-0,11$ & 0,05 \\
\hline Si 0-5 & 0,14 & 0,11 & 0,06 & $-0,43$ & $-0,28$ & $-0,26$ & 0,34 & 0,17 & $-0,20$ & $-0,46$ & $-0,10$ & $-0,12$ & 0,13 & $-0,20$ \\
\hline Si 0-10 & 0,10 & 0,07 & 0,05 & $-0,46$ & $-0,27$ & $-0,28$ & 0,30 & 0,21 & $-0,13$ & $-0,46$ & $-0,17$ & $-0,20$ & 0,14 & $-0,20$ \\
\hline Si 0-15 & 0,08 & 0,05 & 0,03 & $-0,48$ & $-0,25$ & $-0,29$ & 0,32 & 0,25 & $-0,09$ & $-0,37$ & $-0,19$ & $-0,19$ & 0,20 & $-0,21$ \\
\hline Si 0-20 & 0,04 & 0,04 & 0,01 & $-0,43$ & $-0,20$ & $-0,31$ & 0,26 & 0,31 & $-0,09$ & $-0,37$ & $-0,23$ & $-0,24$ & 0,23 & $-0,14$ \\
\hline Al 0-5 & 0,33 & 0,18 & 0,11 & 0,38 & 0,28 & $-0,12$ & $-0,41$ & $-0,22$ & $-0,05$ & 0,23 & $-0,02$ & $-0,21$ & $-0,16$ & 0,29 \\
\hline Al 0-10 & 0,35 & 0,22 & 0,07 & 0,37 & 0,26 & $-0,11$ & $-0,38$ & $-0,22$ & $-0,05$ & 0,24 & $-0,04$ & $-0,18$ & $-0,17$ & 0,30 \\
\hline Al 0-15 & 0,40 & 0,29 & 0,04 & 0,30 & 0,29 & $-0,12$ & $-0,33$ & $-0,22$ & $-0,10$ & 0,28 & $-0,08$ & $-0,11$ & $-0,19$ & 0,34 \\
\hline Al 0-20 & 0,40 & 0,31 & 0,03 & 0,22 & 0,29 & $-0,13$ & $-0,23$ & $-0,20$ & $-0,14$ & 0,33 & $-0,09$ & 0,06 & $-0,22$ & 0,33 \\
\hline C $0-5$ & $-0,08$ & 0,00 & 0,15 & $-0,49$ & $-0,13$ & $-0,42$ & 0,10 & 0,24 & $-0,03$ & $-0,30$ & $-0,24$ & $-0,33$ & 0,29 & 0,25 \\
\hline C $0-10$ & $-0,08$ & 0,00 & 0,16 & $-0,51$ & $-0,14$ & $-0,45$ & 0,08 & 0,22 & $-0,04$ & $-0,37$ & $-0,26$ & $-0,32$ & 0,25 & 0,23 \\
\hline C $0-15$ & $-0,12$ & $-0,07$ & 0,27 & $-0,46$ & $-0,14$ & $-0,50$ & $-0,05$ & 0,14 & 0,00 & $-0,46$ & $-0,25$ & $-0,33$ & 0,19 & 0,22 \\
\hline C $0-20$ & $-0,09$ & $-0,04$ & 0,27 & $-0,45$ & $-0,13$ & $-0,55$ & $-0,05$ & 0,09 & $-0,02$ & $-0,51$ & $-0,29$ & $-0,29$ & 0,16 & 0,25 \\
\hline
\end{tabular}


Os teores foliares de $\mathrm{Si}$ e de $\mathrm{P}$ não diferiram entre os locais, apesar das diferenças nos teores deste último elemento nos solos analisados. Por outro lado, os teores $\mathrm{de} \mathrm{Ca}$ foliar foram significativamente influenciados pelas características dos solos, apresentando alta correlação com os teores de Ca, $\mathrm{Mg}$ e $\mathrm{P}$ trocáveis dos solos (Tabela 8).

Radomski (1998) obteve diferenças significativas nos teores de Si foliar de M. ilicifolia sob diferentes condições de luz, com maior teor em indivíduos crescendo sob sombreamento. Como o Si tem um papel estrutural e de defesa (Epstein, 1994; 1999), sua assimilação e síntese em formas orgânicas teria um menor custo em plantas desenvolvendo-se em ambientes sombreados; ao contrário, em ambientes a pleno sol, esta função estaria compartilhada com a síntese de compostos à base de carbono, como a lignina e os tanantes.

Uma hipótese para a homogeneidade nos teores de Si foliar pode estar relacionada à alta disponibilidade do elemento nos solos estudados, que seria o principal fator regulador da sua absorção, independente das distintas condições de luminosidade a que as populações encontram-se submetidas.

Na Figura 5 está representado o resultado da análise de agrupamento baseada nas características foliares analisadas, massa e área foliar, massa específica foliar, teores de elementos minerais, lignina e fenóis, dos 40 indivíduos amostrados dentre as quatro populações naturais.
Pela análise de componentes principais (Tabela 9), verificou-se que seis vetores explicam $81,5 \%$ da variação total entre grupos, o que corresponde às variáveis fenóis totais, Al, Si, Ca, massa foliar e Fe (Tabela 10).

Tabela 9. Valores dos 17 componentes principais das características fitoquímicas das populações naturais de Maytenus ilicifolia.

\begin{tabular}{cccc}
\hline Vetor & Autovalores & $\begin{array}{c}\text { Variância } \\
\text { relativa }\end{array}$ & $\begin{array}{c}\text { Variância } \\
\text { acumulada }\end{array}$ \\
\hline 1 & 6,5166 & 36,20 & 36,20 \\
2 & 2,8762 & 15,98 & 52,18 \\
3 & 1,7773 & 9,87 & 62,06 \\
4 & 1,3119 & 7,29 & 69,34 \\
5 & 1,1820 & 6,57 & 75,91 \\
6 & 1,0039 & 5,58 & 81,49 \\
7 & 0,6858 & 3,81 & 85,30 \\
8 & 0,6153 & 3,42 & 88,72 \\
9 & 0,5032 & 2,80 & 91,51 \\
10 & 0,3893 & 2,16 & 93,67 \\
11 & 0,3248 & 1,80 & 95,48 \\
12 & 0,2500 & 1,39 & 96,87 \\
13 & 0,2073 & 1,15 & 98,02 \\
14 & 0,1391 & 0,77 & 98,79 \\
15 & 0,1153 & 0,64 & 99,43 \\
16 & 0,0914 & 0,51 & 99,94 \\
17 & 0,0108 & 0,06 & 100,00 \\
\hline
\end{tabular}

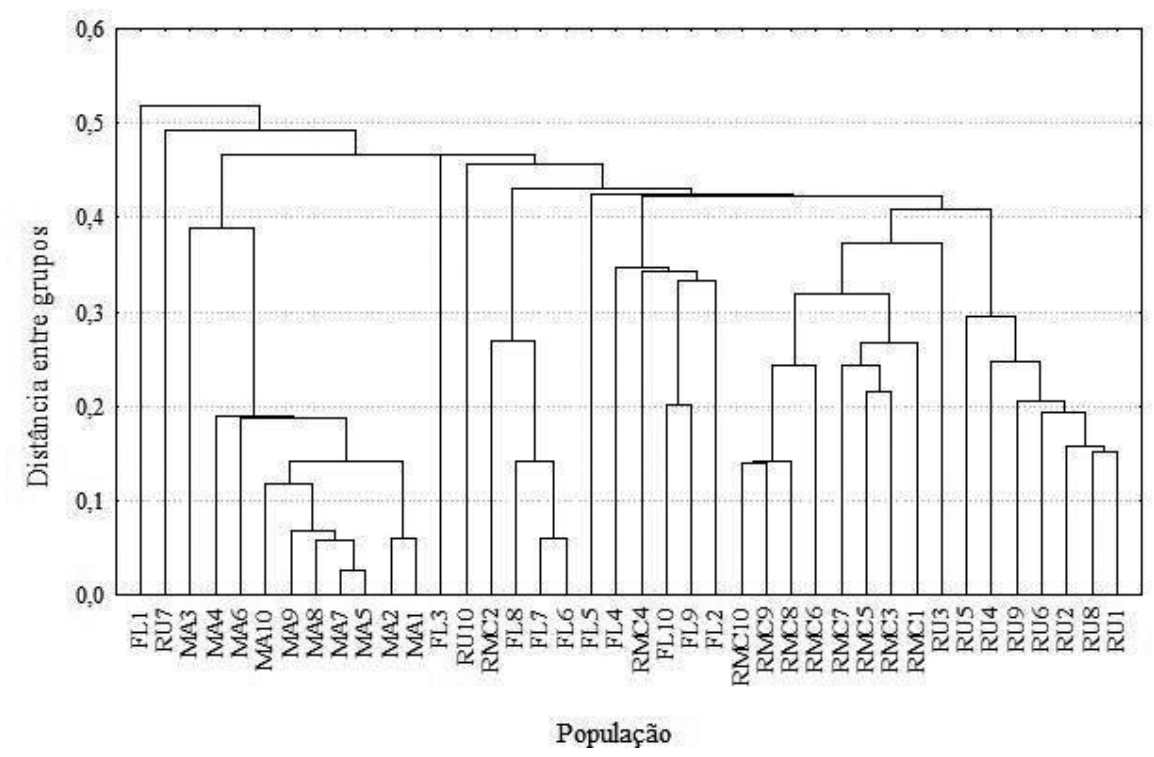

Figura 5. Análise de agrupamento baseada na similaridade das características foliares avaliadas nas quatro populações naturais de Maytenus ilicifolia. 
Tabela 10. Valores dos cinco vetores com maior participação nos componentes principais das características fitoquímicas das populações naturais de Maytenus ilicifolia.

\begin{tabular}{lcccccc}
\hline Variável & Vetor $\mathbf{1}$ & Vetor $\mathbf{2}$ & Vetor 3 & Vetor 4 & Vetor 5 & Vetor 6 \\
\hline Massa & $-0,1947$ & 0,6315 & $-0,2710$ & $-0,1171$ & $-0,5767$ & $-0,0672$ \\
Área foliar & $-0,5872$ & 0,5065 & $-0,4779$ & $-0,2031$ & $-0,2118$ & $-0,1744$ \\
Massa específica & 0,8766 & $-0,0692$ & 0,2591 & 0,0910 & $-0,0875$ & 0,0871 \\
$\mathrm{~N}$ & $-0,4948$ & $-0,5258$ & 0,1681 & $-0,4683$ & $-0,0735$ & 0,0063 \\
$\mathrm{P}$ & $-0,5143$ & 0,3736 & 0,5512 & $-0,1477$ & $-0,0093$ & $-0,1438$ \\
$\mathrm{~K}$ & $-0,7861$ & $-0,2338$ & 0,1985 & $-0,1734$ & $-0,2184$ & $-0,1867$ \\
$\mathrm{Ca}$ & $-0,5854$ & 0,4869 & $-0,0428$ & 0,5010 & 0,2227 & 0,0112 \\
$\mathrm{Mg}$ & $-0,7028$ & $-0,2966$ & $-0,1956$ & 0,3570 & 0,1187 & 0,0122 \\
$\mathrm{Fe}$ & $-0,3885$ & $-0,6255$ & $-0,0699$ & $-0,0075$ & 0,0528 & $-0,5113$ \\
$\mathrm{Mn}$ & $-0,5022$ & $-0,0430$ & 0,3123 & 0,0195 & 0,2311 & 0,4691 \\
$\mathrm{Cu}$ & $-0,0965$ & $-0,5857$ & 0,3878 & 0,0793 & $-0,5135$ & 0,1466 \\
Zn & $-0,4697$ & 0,3705 & 0,5051 & $-0,0150$ & 0,3228 & $-0,2117$ \\
$\mathrm{Al}$ & $-0,2907$ & $-0,6889$ & $-0,3092$ & 0,4314 & $-0,0303$ & $-0,1241$ \\
$\mathrm{Si}$ & $-0,1217$ & $-0,2055$ & $-0,5969$ & $-0,4791$ & 0,4036 & 0,1670 \\
Lignina & $-0,7962$ & $-0,0691$ & 0,1269 & $-0,3306$ & 0,1873 & 0,0225 \\
Fenóis totais & 0,8879 & $-0,0199$ & 0,0880 & $-0,1006$ & 0,1536 & $-0,3076$ \\
Fenóis não tanantes & 0,7790 & $-0,1563$ & $-0,0308$ & $-0,2338$ & $-0,0166$ & 0,2132 \\
Tanantes & 0,8000 & 0,0223 & 0,1106 & $-0,0485$ & 0,1822 & $-0,4170$ \\
\hline & & & & & \\
\hline
\end{tabular}

Pode-se observar a formação de quatro grupos principais: Grupo 1, com indivíduos pertencentes exclusivamente à População Manasa; Grupo 2, com três indivíduos pertencentes à População Flona e um indivíduo da População RMC; Grupo 3, com quatro indivíduos da População Flona e um da População RMC; Grupo 4, com oito indivíduos da População RMC e oito indivíduos da População Rureco.

Dentre as populações, Flona é a que apresenta uma maior dispersão dos indivíduos, ou seja, uma menor similaridade dos indivíduos para as características avaliadas. Este fato é consequência da maior variabilidade ambiental observada nesta população, principalmente devido às diferentes características edáficas. No Grupo 2, os indivíduos FL6, FL7 e FL8 de Flona pertencem à classe de solo GXbd, cuja principal característica é a flutuação constante do lençol freático, e a deposição de sedimentos em função das inundações periódicas do Rio das Antas, o que promove uma dinâmica físico-química diferenciada no solo, implicando em possíveis diferenças na expressão fenotípica como fator de adaptação da espécie a uma condição edáfica particular. No Grupo 3, os indivíduos FL9 e FL10 pertencem ao solo CUbd, que diferencia-se de GXbd principalmente pelos menores teores de $\mathrm{Ca}, \mathrm{Mg}$ e $\mathrm{Mn}$ disponíveis na camada de 0-20 $\mathrm{cm}$. Também cabe mencionar que os indivíduos desta população encontram-se expostos a diferentes ambientes lumínicos, resultando em diferenças principalmente nos teores de liginina e fenóis, como discutido anteriormente.

Comparando-se os grupos, nota-se uma menor similaridade fitoquímica entre indivíduos pertencentes às populações de Manasa e Rureco.

Em relação a estas populações, Steenbock (2003), avaliando a estrutura genética das mesmas, observou que em Manasa há maior possibilidade de troca de alelos entre os indivíduos, devido à ocorrência de apenas um tipo floral por indivíduo, ou seja, os que apresentam flores funcionalmente femininas ou masculinas, ao contrário de Rureco, onde os indivíduos apresentam os dois tipos florais. Isso sugere que a variação genética dentro da população de Manasa seja menor que a existente em Rureco, em função das diferentes taxas de endogamia. Também observado pelo autor é a associação da ocorrência dos tipos florais às distintas condições edafoclimáticas das duas populações.

Neste sentido, Jing \& Coley (1990) citam que a diferenciação de populações em indivíduos masculinos e/ou femininos, em função de distintas condições ambientais, também leva a diferenças na produção de compostos secundários ligados à defesa vegetal, como 
é o caso dos taninos. Segundo os autores, indivíduos femininos alocariam mais recursos para a síntese de compostos de defesa do que indivíduos masculinos, de modo a garantir a reprodução e perpetuação da espécie, em detrimento do crescimento vegetativo.

Além da reprodução sexuada, M. ilicifolia apresenta reprodução vegetativa via emissão de brotações radiculares, sendo observado em todas as áreas. Entretanto, essa pode ser uma forma preferencial de reprodução em condições de maior sombreamento, onde a disponibilidade de luz seria uma limitante para a produção de flores e frutos. Neste caso, caberia, em futuros estudos, vincular a análise fitoquímica, em particular a quantificação dos teores de fenóis, aos tipos florais e sistemas de reprodução de M. ilicifolia, identificando as relações entre estas características em distintas condições ambientais.

\section{Conclusões}

As populações de $M$. ilicifolia apresentam uma significativa plasticidade ambiental, desenvolvendose sobre diversas condições de fertilidade e regime hidromórfico dos solos, e sob distintos ambientes lumínicos.

A quantidade de luz disponível no verão (PAR) foi o principal regulador da absorção de $\mathrm{N}$ e $\mathrm{K}$ e da síntese de fenóis totais em M. ilicifolia, resultando em maior produção de biomassa na população a pleno sol devido à maior alocação de compostos baseados no carbono.

A relação inversa entre a produção de taninos e lignina indica que $M$. ilicifolia apresenta uma regulação interna para a produção "racional" dos compostos fenólicos, cujas vias de síntese são ativadas/desativadas em função de fatores ambientais, em particular da luz.

\section{Agradecimentos}

À Fapesp, pelo auxílio pesquisa, e ao CNPq, pela bolsa, ambos concedidos ao primeiro autor. À Embrapa Florestas, nas pessoas de Arnaldo de Oliveira Soares, Claudia Mara Pereira, Irineu Oliniski, Paula Pucci, Sidney Vicente Shaffer (in memorian) e Wilson Maschio, pelo fundamental apoio nos trabalhos de campo e laboratório. Ao Instituto Chico Mendes - Floresta Nacional de Irati, à Manasa Florestal e à Fundação para o Desenvolvimento da Região Centro-Oeste (Rureco), pela disponibilização de suas áreas para a coleta de amostras.

\section{Referências}

BERNARDI, H. H.; WASICKY, M. Algumas pesquisas sobre a "Espinheira Santa" ou "Cancerosa" M. ilicifolia Martius, usada como remédio popular no Rio Grande do Sul. Santa Maria: URGS, 1959. 46 p.

BITTENCOURT, J. V. M. Variabilidade genética em populações naturais de M. ilicifolia por meio de marcadores RAPD. Curitiba: UFPR, 2000. 58p. Dissertação (Mestrado em Agronomia, Área de concentração: Produção Vegetal) - Setor de Ciências Agrárias Universidade Federal do Paraná, Curitiba, PR.

BRASIL. MINISTÉRIO DA SAÚDE. PORTARIA GM No 3.237 , de 24 de dezembro de 2007. Aprova as normas de execução e de financiamento da assistência farmacêutica na atenção básica em saúde. Disponível em: <http://dtr2004.saude.gov.br/dab/docs/ legislacao/portaria_gm_3237_2008.pdf $>$. Acesso em: 10 jun. 2009.

CARLINI, E. L. A (coord.). Estudo de ação antiúlcera gástrica de plantas brasileiras: M. ilicifolia (Espinheira-Santa) e outras. Brasília: CEME/AFIP, 1988. 87p.

CARVALHO-OKANO, R. Estudos taxonômicos do gênero Maytenus Mol. emend. Mol. Celastraceae) do Brasil extraamazônico. 1992. 261 f. Tese (Doutorado em Ciências Biologia Vegetal) - Instituto de Biologia, Universidade Estadual de Campinas, Campinas

CARVALHO, R.; FURTINI NETO, A. E.; CURI, N.; FERNANDES, L. A.; OLIVEIRA JÚNIOR, A. C. Dessorção de fósforo por silício em solos cultivados com eucalipto. Revista Brasileira de Ciência do Solo, v. 24, n.1, p. 69-74, 2000.

CARVALHO-PUPATTO, J. G.; BÜLL, L. T.; CRUSCIOL, C. A. C.; MAUAD, M.; SILVA, R. H. da. Efeito de escória de alto forno no crescimento radicular e na produtividade de arroz. Pesquisa Agropecuária Brasileira, v. 38, n. 11, p. 1323-1328, 2004.

COLEY, P. D.; BRYANT, J. P.; CHAPIN III, F. S. Resource availability and plant antiherbivore defense. Science, v. 230, n. 4728, p. 895-899, 1985.

CIPOLLINI, D. Stretching the limits of plasticity: can a plant defend against both competitors and herbivores? Ecology, v. 85, n. 1, p. 28-37, 2004.

EMBRAPA. Serviço Nacional de Levantamento e Conservação de Solos. Levantamento de reconhecimento dos solos do Estado do Paraná. Londrina: EMBRAPA-SNLCS: IAPAR, 1984. 2 t. 791 p. (EMBRAPA-SNLCS. Boletim de Pesquisa, 27; IAPAR-Projeto Especial Levantamento de Solos. Boletim Técnico, 16). Convênio: SUDESUL-EMBRAPA-GOVERNO DO ESTADO DO PARANÁ: IAPAR.

EPSTEIN, E. Silicon. Annual review of plant physiology and plant molecular biology, v. 50, n. 1., p. 641-664, 1999.

EPSTEIN, E. The anomaly of silicon in plant biology. Proceedings of the National Academy of Sciences of the United States of America, v. 91, n.1, p.11-17, 1994.

EXLEY, C. Silicon in life: A bioinorganic solution to biorganic essentiality. Journal of Inorganic Biochemistry, v. 69, n. 3, p.139144, 1998. 
GOTO, M.; EHARA, H.; KARITA, S.; TAKABE, K.; OGAWA, N.;YAMADA, Y.; OGAWA, S.;YAHAYA, M.S.; MORITA, O. Protective effect of silicon on phenolic biosynthesis and ultraviolet spectral stress in rice crop. Plant Science, v. 164, p. 349-356, 2003.

HAAG, H. P. (Coord.). Nutrição mineral de Eucalyptus, Pinus, Araucaria e Gmelina no Brasil. Campinas: Fundação Cargill, 1983. 202p.

JOHNSON, R. A.; WICHERN, D. W. Applied multivariate statistical analysis. 3. ed. New Jersey: Prentice-Hall, 1992. 642 p

KABATA-PENDIAS, A.; PENDIAS, H. Trace Elements in Soils and Plants. 2.ed. Boca Raton: CRC, 1991.365p.

KORNDÖRFER, G. H.; COELHO, N. M.; SNYDER, G. H.; MIZUTANI, C. T. Avaliação de métodos de extração de silício em solos cultivados com arroz de sequeiro. Revista Brasileira de Ciências do Solo, v. 23, p.101-106, 1999a.

KORNDÖRFER, G. H.; ARANTES, V. A.; CORREA, G. F.; SNYDER, G. H. Efeito do silicato de cálcio no teor de silício no solo e na produção de grãos de arroz de sequeiro. Revista Brasileira de Ciências do Solo, v. 23, p. 635-641, 1999 b.

JANZEN, D.H. Ecologia vegetal nos trópicos. São Paulo, EPU, EDUSP, 1980. 79p.

JING, S. W.; COLEY, P. D. Dioecy and herbivory: the effect of growth rate on plant defense in Acer negundo. Oikos, v. 58, p. 369-377, 1990.

KUREPIN, L. V.; WALTON, L. J.; REID, D. M.; PHARIS, R. P.; CHINNAPPA, C. C. Growth and ethylene evolution by shade and sun ecotypes of Stellaria longipes in response to varied light quality and irradiance. Plant, Cell and Environment, v. 29, n. 4, p. 647-652, 2006.

LARCHER, W. Ecofisiologia vegetal. São Paulo: EPU, 1986. 319p.

LEITE, P. F. As diferentes unidades fitoecológicas da Região Sul do Brasil: proposta de classificação. 1994. 160 f. Dissertação (Mestrado em Ciências Florestais) - Setor de Ciências Agrárias, Universidade Federal do Paraná, Curitiba.

MAZZA, M. C. M.; MAZZA, C. A. da SILVA; RADOMSKI, M. I.; SOARES, A. de O.; RACHWAL, M. F. G.; SANTOS, J. E. dos. Caracterização de populações e habitats de Maytenus ilicifolia na Floresta Nacional de Irati, região centro-sul do estado do Paraná. In: CONGRESSO DE ECOLOGIA DO BRASIL, 6., 2003, Fortaleza. 2003. Anais de trabalhos completos. Fortaleza: Universidade Federal do Ceará, 2003. p. 211-212.

MINEROPAR. Levantamento geoquímico multielementar do Estado do Paraná: geoquímica de Solo Horizonte B: relatório final de projeto. Curitiba, v. 1, 2005.

NOGUEIRA, A. R. de A.; SOUZA, G. B. de (Eds.). Manual de Laboratórios: solo, água, nutrição vegetal, nutrição animal e alimentos. São Carlos, SP: Embrapa Pecuária Sudeste. 2005. 334 p. il.

OLIVEIRA, Y. M. M. de. Investigation of remote sensing for assessing and monitoring the Araucaria Forest Region of Brazil. 1999. 247 f. Doctor (Philosophy Thesis) - University of Oxford, Oxford.

RADOMSKI, M. I. Caracterização ecológica e fitoquímica de Maytenus ilicifolia Mart., em populações nativas, no município da
Lapa, Paraná. 1998. 97p. Dissertação (Mestrado em Agronomia, Área de concentração em Ciência do Solo) - Setor de Ciências Agrárias da Universidade Federal do Paraná, Curitiba - PR.

RADOMSKI, M. I.; WISNIEWSKI, C.; CURCIO, G. R.; RACHWAL, M. G.; SANTOS, C. A. M. Caracterização de ambientes de ocorrência natural e sua influência sobre o peso específico e o teor de polifenóis totais de folhas de espinheirasanta (Maytenus ilicifolia Mart.). Revista Brasileira de Plantas Medicinais, v. 6, n. 2, p. 36-43, 2004a.

RADOMSKI, M.I.; PERECIN, M. B.; STEENBOCK, W. Aspectos ecológicos de espécies de espinheira-santa. In: REIS, M. S. dos; SILVA, S. R. (Org.). Conservação e uso sustentável de plantas medicinais e aromáticas: Maytenus spp., espinheirasanta. Brasília, DF: Ibama,, 2004b. p. 93-114. (Coleção plantas medicinais e aromáticas, v. 1).

REICHER, F.; SIERAKOWSKI, M. R.; CORRÊA, J. B. C. Determinação espectrofotométrica de taninos pelo reativo fosfotúngstico-fosfomolíbdico. Arquivos de Biologia e Tecnologia, v. 24, n. 4, p. 407-411, 1981.

SANTOS, H. G. dos; JACOMINE, P. K. T.; ANJOS, L. H. C. dos; OLIVEIRA, V. A. de; OLIVEIRA, J. B. de; COELHO, M. R.; LUMBRERAS, J. F.; CUNHA, T. J. F. da (Ed.). Sistema brasileiro de classificação de solos. 2. ed. Rio de Janeiro: Embrapa Solos, 2006. 306 p.

SCHEFFER, M. C. Sistema de cruzamento e variação genética entre populações e progênies de espinheira-santa. 2001. 104 f. Tese (Doutorado em Ciências Florestais) - Setor de Ciências Agrárias, Universidade Federal do Paraná, Curitiba.

SILVA, F. C. da (Org.). Manual de análises químicas de solos, plantas e fertilizantes. Brasília, DF: Embrapa Comunicação para Transferência de Tecnologia; Rio de Janeiro: Embrapa Solos; Campinas: Embrapa Informática Agropecuária, 1999. 370 p.

STEENBOCK, W. Fundamentos para o manejo de populações naturais de espinheira-santa, Maytenus ilicifolia Mart. ex Reiss (Celastraceae). Florianópolis: UFSC, 2003. 145 p. Dissertação (Mestrado em Recursos. Genéticos Vegetais) - Programa de PósGraduação, UFSC, Florianópolis, SC.

STELLFELD, C. A. A espinheira-santa: contribuição ao estudo farmacognóstico. Boletim da Associação Brasileira de Pharmacêuticos, v. 15, p. 551-571, 1934.

TAIZ, L.; ZEIGER, E. Fisiologia Vegetal. 3. ed. Porto Alegre: Artmed, 2004. 719 p. il.

TURNBULL, M. H. The effect of light quantity and quality during development on the photosynthetic characteristics of six Australian rainforest tree species. Oecologia, v. 87, p. 110-117, 1991.

VARANDA, E. M.; RICCI, C. V.; BRASIL, I. M. Espécies congenéricas da mata e do cerrado: teor de proteínas e compostos fenólicos. Boletim de Botânica da Universidade de São Paulo, v. 17, p. 25-30, 1998.

VARLET-GRANCHER, C.; MOULIA, B.; SINOQUET, H.; RUSSEL, G. Spectral modification of light within plant canopies: how to quantify its effects on the architecture of the plant stand. In: VARLET-GRANCHER, C.; BONHOMME, R.; SINOQUET, H. (eds.). Crop structure and light microclimate: characterization and application. Paris: INRA, p. 427-451, 1993.

Recebido em 07 de abril de 2009 e aprovado em 14 de junho de 2010 